\title{
1.26 Cognition in Invertebrates
}

R Menzel and B Brembs, Freie Universität Berlin, Berlin, Germany

M Giurfa, Université Paul Sabatier, Toulouse,

France

(c) 2007 Elsevier Inc. All rights reserved.

1.26.1 Introduction

404

1.26.2 Dominance of Innate Behavior 405

1.26.2.1 Selection of Habitat, Feeding, and Foraging 405

$\begin{array}{ll}\text { 1.26.2.2 Early Programmed Learning } & 407\end{array}$

1.26.3 Elemental Forms of Associative Learning 407

1.26.3.1 Invertebrate Classical Conditioning 408

1.26.3.2 Invertebrate Operant Conditioning 410

1.26.3.3 Invertebrate Composite Operant Conditioning 412

1.26.4 Nonelemental Forms of Associative Learning 413

1.26.5 Integration Across Sensory Modalities and Rule Learning 416

1.26.5.1 Selective Attention $\quad 416$

1.26.5.2 Rule Learning $\quad 417$

1.26.5.3 Conditional Discriminations: Occasion Setting and Contextual Learning 418

1.26.6 Memory Systems $\quad 420$

1.26.6.1 Physiological Correlates of Memory Systems $\quad 421$

1.26.6.2 Working Memory: Capacity and Duration 422

1.26.6.3 Reconsolidation $\quad 423$

1.26.6.4 Ecology of Memory Systems

1.26.7 Representation and Planning, Observatory Learning; Navigation; Communication and
Individual Recognition

$\begin{array}{ll}\text { 1.26.7.1 Observatory Learning } & 425\end{array}$

$\begin{array}{ll}\text { 1.26.7.2 Navigation } & 426\end{array}$

1.26.7.3 Communication $\quad 429$

1.26.7.4 Individual Recognition 431

1.26.7.5 Collective Cognition $\quad 432$

1.26.8 Conclusion

433

\section{Glossary}

classical

conditioning

cognition

episodic memory

explicit knowledge

habituation
Learning about relationships in the environment.

The use and handling of knowledge.

In humans the consciously recollected memory for facts and events as they are characterized by their contents (what), their time of occurrence (when), and their locations (where). Episodic-like memory in animals stores the what, when, and where for important events (food). (See Section 1.26.6.)

Knowledge encoded as representations, such as places, facts, and events.

Reduction of responsiveness after multiple application of the same stimulus. Habituation is discriminated from sensory adaptation and motor fatigue by its stimulus specificity, spontaneous recovery, dishabituation by a strong stimulus, and by a saving effect (stronger response decrement after multiple sessions of habituation).

implicit knowledge Knowledge encoded in actions and associations, for example, acquired through predictive learning.

innate preferences, innate stereotypy nonelemental learning

occasion setting on phylogenetic memory.

Associative forms of learning in which individual events are ambiguous and only logical combinations of them can be used to solve the problem. Examples are described in Section 1.26.4.

A learning situation in which a stimulus, the occasion setter, sets the occasion for when a predictive
Simple forms of behavior based 
operant

conditioning

phylogenetic

memory

predictive learning

rule learning

search image

sensitization

working memory relationship applies. Contextual learning is closely related to occasion setting (see Section 1.26.5.3). Learning about the consequences of one's own behavior.

The species' memory. The information stored in the genome as acquired by mutation and selection during evolution.

Using operant and classical conditioning to predict future events. The ability of an animal to infer rule information from a number of different examples connected by a common feature (see Section 1.26.5).

Animals searching for a target the knowledge about which has either been learned or is known on the basis of innate information (phylogenetic memory).

Increase of responsiveness after the experience of a strong stimulus.

A transient form of active memory that combines both information retrieved from a permanent store and actual incoming information (see Sections 1.26.6.1 and 1.26.6.2)

\subsubsection{Introduction}

Animals are characterized at all levels of neural complexity by a continuous flow of energy, material, and information. Behavior is an animal's means for surviving the destructive forces of entropy on both long and short timescales. Evolution maintains and in most cases improves complexity over multiple reproductive life cycles. To achieve this goal the environment evaluates stochastic changes in the material inheriting the organism's organizational information, and the information thus selected is transmitted from one generation to the next. Thus, evolution is in essence an information-creating (in some cases informationdestructing) process, and the inherited information characterizing each organism may be called the species-specific phylogenetic memory.

Animals also collect and store individual memories on a short timescale through learning by experience. Information based on repeated experience gathered by an individual organism in attempts to cope with the immediate demands of the environment is evaluated through environmental feedback, either reinforcing or reducing the impact of the underlying cellular mechanisms on the organism's future responses. Individual memory is therefore based on learning, which is the capacity to modify the individual's behavior on a relatively permanent basis through the acquisition of new information based on individual experience. Both kinds of memory, phylogenetic and individual memory, can be understood as organismic devices to predict the future and to reduce the environment's uncertainty. They are thus instantiations that link the past with the future, creating a present that is better adapted to the organism's requirements. Individual memory is incorporated into the framework provided by the phylogenetic memory, facilitating and shaping individual learning processes. Thus, the framework within which experience-based learning occurs is tuned to the demands expected during the individual organism's lifetime.

Cognition can be viewed as the integrating process that utilizes both forms of memory, creates an internal representation of the world and a basis for expecting the future of the animal's own actions within the experienced environment. It thus allows the animal to decide between different options in reference to the expected outcome of its potential actions. All these processes occur as intrinsic properties of the nervous system and provide an implicit form of knowledge for controlling behavior. None of these processes need to - and certainly will not become explicit within the nervous systems of most invertebrates, but, as this review will show, such processes must be assumed to also exist in invertebrates with proper nervous systems (albeit over a large range of levels of complexity) to account for their behavior.

The results of these integrating cognitive processes are manifold and can span a gradient of possibilities. In such a gradient, at one extreme, one can find organisms dominated by their inherited information and having minimal experience-based adaptation; at the other extreme, phylogenetic memory may merely provide a broad framework, and experience-based memory will dominate. The factors determining the specific combination and weights of inherited and experience-dependent memories in an individual are not yet well understood. A short individual lifetime, few environmental changes during a lifetime, and highly specialized living conditions will favor the dominance of inherited information; a longer individual lifetime, less adaptation to particular environmental niches, and rapid environmental changes relative to the life span reduce the impact of phylogenetic memory and increase the role of individual learning. Social living style also seems to be a defining factor for the balance between these different forms of memory. In social animals, learning has to play an important role, because the species' genome must equip the individuals for acting under much 
more variable environmental conditions because of the society's longer lifetime, and because the communicative processes within the society demand a larger range of cognitive processes.

It has also been suspected that the complexity and size of the nervous system may be related to the dominance of inherited or experience-dependent memories, in the sense that individual learning demands a larger nervous system having greater complexity. However, the primary parameter determining the size of the nervous system is body size, and secondary parameters such as richness of the sensory world, cognitive capacities, and abundance of motor patterns are difficult to relate to brain size, because such parameters cannot be adequately measured, and thus a comparison based on them is practically impossible between animals adapted to different environments. Although the relationship between brain size and cognitive capacity is still unclear, it is obvious that animals differ with respect to their sensory, motor, and cognitive capacities (see Evolution of the Elephant Brain: A Paradox between Brain Size and Cognitive Behavior). Individual learning within the species-specific sensory and motor domains will lead to more flexible behavior, and thus to more advanced cognitive functions. Predicting the future will therefore be less constrained, and more options will enrich the animal's present state.

Although we do not attempt to strictly define the cognitive components of behavior, the essential characteristics of cognition are: (1) rich and crosslinked forms of sensory and motor processing; (2) flexibility and experience-dependent plasticity in choice performance; and (3) long-term (on the timescale of the respective animal's life span) adaptation of behavioral routines. These three features allow the creation of novel behavior through different forms of learning and memory processing. Among them, we can cite (1) rule learning, (2) observatory learning during navigation and imitation, and (3) recognition of group members and individuals in a society. All these characteristics are based on implicit forms of knowledge and do not require any explicit (or conscious) processing. However, internal processing at the level of working memory (or representation) as an indication of rudimentary forms of explicit processing may exist in invertebrates within the context of observatory learning and social communication, and will be discussed.

We shall first consider forms of behavior that are dominated by innate components, and raise the questions of how innate and learned behavior are related and whether innate behavior involves cognitive components. The following sections focus on experience-dependent forms of behavior and follow in the order of ascending complexity: from elemental forms of associative learning to rule learning and observatory learning in navigation and communication. A key component in cognition is memory, not only as a storing device, but also in the form of working memory, the implicit form of representation which may provide the substrate for neural operations underlying decision making in relation to the expected outcome of the animal's actions. Both aspects of memory will be discussed.

\subsubsection{Dominance of Innate Behavior}

Invertebrates are dominated to a great extent by innate behavior, and some researchers have gone so far as to characterize insects and crustacea as "mindless machines" (Gould and Gould, 1982). Historically, innate preferences for biologically relevant sensory cues were used to characterize innate behavior. This view, which is still represented in ecological approaches to invertebrate behavior, assumes that invertebrates are irresistibly attracted to some sensory cues, which act as magnets on different phases of invertebrate behavior. At the origin of this notion, one can certainly find the preconception that invertebrates are essentially reflex machines with limited forms of experience-dependent plasticity. Although we shall focus on learningrelated flexibility as a characteristic of invertebrate cognition, it is worthwhile to first recognize the complexity and richness of innate sensory-motor routines and their relationship to learned behavior.

\subsubsection{Selection of Habitat, Feeding, and Foraging}

Earthworms not only eat their way through the soil, swallowing the dirt they encounter, but feed selectively in many ways, as described by Darwin (1882). They leave unsuitable ground and select more productive soil, and they crawl out of their burrows at night to feed on the leaves of certain plant species. The earthworm grasps the tapered tip opposite the petiole, and then pulls the leaf back into the burrow to be eaten underground (Edwards and Lofty, 1972). Selection of habitat and food sources is commonly based on 'search images', innate sensoryneural filters that inform the animal about the desired food. Innate preferences are difficult to demonstrate because they require an absolute control of the animal's experience prior to the experiments in which it is confronted with the stimuli to be tested. If such control is absent, it is practically impossible to conclude anything about potential innate preferences, because the animal's 
choice may simply reflect its previous experience with natural stimuli in its environment. Despite the difficulty of achieving such a control, some studies have appropriately addressed the question of innate preferences and showed that such preferences do indeed exist. However, they have also pointed out that choice behavior driven by this programmed signal responding is subjected to dramatic modifications based on first experiences. Thus, although such preferences may exist, they seem to be essentially useful in guiding the animals' behavior in their first confrontations with the external world.

A clear example of changes in innate preferences due to previous experiences is provided by the cuttlefish Sepia officinalis. In this animal, Darmaillacq et al. (2004a) recently showed that on the third day post-eclosion, when the young cuttlefish have consumed their vitellogenic resources, they exhibit clear preference for shrimps over crabs and young fish of comparable sizes. However, by making the preferred prey distasteful with quinine, it is possible to induce a preference for an originally nonpreferred prey item in 3-day-old and naïve cuttlefish, demonstrating the flexibility of this initial behavioral preference in response to previous individual experience. Such a learning is extremely fast (Darmaillacq et al., 2004b), a fact that indicates to what extent innate preferences may be easily modified.

In insects, several studies have addressed the question of appetitive choice behavior as driven by innate preferences. In the moth Helicoverpa armigera, for instance, Cunningham et al. (2004) have shown that experience-deprived adult moths raised in isolation exhibit innate preferences for phenylacetaldehyde when tested in dual-choice wind tunnel tests. Again, this preference changes rapidly if a nonpreferred volatile substance is paired with a feeding stimulus (sucrose solution). In honeybees, a similar result was found with respect to color preferences. Honeybees whose visual experience was strictly controlled in a flight cage in which no rewards were provided on colored targets showed consistent preferences for some dominant wavelengths when presented with such targets in their first active foraging flight (Giurfa et al., 1995). Colors preferred by naïve bees were human-blue and human-yellow, which correspond to those hues that experienced bees learn faster and better when trained with a single color/sucrose reward association (Menzel, 1967). However, all other hues which are originally not chosen rapidly become preferred if they are explicitly paired with sucrose reward (Giurfa et al., 1995).
The intimate connection between innate and learned behaviors and their mutual replacement for behavioral control also becomes obvious in host selection by the two species of the stem-borer parasitoids Cotesia glomerata and Cotesia flavipes (Hymenoptera, Braconidae) (Geervliet et al., 1998; Potting et al., 1997; Vet, 1996; Vet et al., 1995). While C. flavipes exhibits innate preference for its host's odors, the larvae of Pieris brassica (Lepidoptera), the closely related C. glomerata, learns the varying odor profiles of its Pieris host larvae, which depend on the plants it feeds on. No other differences in behavior between these two species were found, indicating that experiencedependent adjustment and innate stereotypy are two close strategies and are not related to any great differences between the neural systems involved.

The interesting question of whether innate preferences are deleted or inhibited by experience (and thus available at different moments of an invertebrate's life) has been addressed in bumblebees (Gumbert, 2000). Naïve bumblebees show color preferences that are similar to those exhibited by honeybees. After being trained to a given colored target by pairing it with sucrose reward, the bees chose novel test colors according to their similarity to the trained color. Thus, bees generalized their choice from the trained to novel, similar colors; however, if the trained and the test colors were perceptually dissimilar to the bees such that generalization did not occur, the original innate color preferences reappeared and guided the bees' choices. Thus, bumblebees show innate preferences for certain colors not only prior to color learning but also after intensive learning when choosing among very different novel colors (Gumbert, 2000).

These chosen examples among many similar ones from other invertebrates allow us to conclude that (1) invertebrates exhibit innate preferences for signals allowing to rapidly and efficiently detect biologically relevant stimuli in their first encounters with them; (2) such preferences can be drastically modified by the animals' experience such that plasticity and not rigidity of behavior should be underlined in the case of innate preferences; and (3) such preferences can be available in experienced adults such that they can be retrieved under particular circumstances, when the learned information is no longer useful. It is still unknown how these preferences can be hard-wired in the naïve invertebrate nervous system, but they have been selected through the species' evolutionary history and thus belong to its phylogenetic memory. 


\subsubsection{Early Programmed Learning}

Early programmed learning occurs in young animals exposed to particular stimuli during a critical period. As a consequence of this process, also called imprinting, the animal later prefers the 'imprinted' stimuli. This kind of programmed learning has also been documented in invertebrates, particularly in insects. For instance, mosquitoes Culex quinquefasciatus use chemical cues to locate suitable water pools for oviposition. An individual mosquito's preferences for these odors can be altered greatly by prior experience (McCall and Eaton, 2001). In particular, change in odor preferences could be demonstrated following exposure to the odor during development or pupal eclosion, suggesting that some form of larval or early adult imprinting occurred.

In social Hymenoptera, parental relationships involve the use of specific signals, some emitted by the young animals, and others by the adults. Some of the signals are learned during an early experience (Dobson, 1989). The behavioral responses of parasitic wasps to chemical cues from their hosts and host plants are known to be affected by genetic and environmental components. Gandolfi et al. (2003) have shown that true pre-imaginal learning of olfactory cues occurs in the parasitic wasp Hyssopus pallidus. While parasitoids are not able to learn the fruit cues in the adult stage, exposure to fruit odor at early pre-imaginal stages significantly increases the adult response to frass from fruit-fed caterpillars (Gandolfi et al., 2003). The olfactory memory persisted through metamorphosis, with a retention time of 14 days. Pre-imaginal learning was not confined to fruit cues, but was also demonstrated for menthol, an olfactory host- and fruit-independent cue.

A fascinating case of imprinting in insects is provided by studies on slave-making ants, which are characterized by socially parasitic founding of colonies (i.e., colonies in which two species of social insects coexist, one of which is parasitically dependent on the other) and the pillage of broods from neighboring host colonies during slave raids. Slavemaking ants invade colonies of other ant species and transport the pupae back to their own nest. Adults emerging from these pupae react and work for the slave-making species as if it were its own species (Isingrini et al., 1985; Carlin and Schwartz, 1989). The basis for such phenomenon may be olfactory imprinting processes by which the slave ants learn to recognize the slave makers as members of their own species. This hypothesis is subject to debate because it has been argued, for instance, that the capacity of larvae to imprint on the odor of their natal nest might make an ant species unsuitable for slave makers. An ant worker pillaged as pupa after preimaginal imprinting might identify slave-maker brood as alien and refuse to care for them (D'Ettorre and Heinze, 2001). However, the problem is solved if the hydrocarbon cuticular profiles, the distinctive olfactory mark of each species, of both the slaves and the slave makers are similar. This seems to indeed be the case (Lenoir et al., 2001; D'Ettorre et al., 2002).

The mechanistic basis of early olfactory learning has been studied in some insects. In the fruit fly Drosophila melanogaster, Devaud et al. (2003) showed that synaptogenesis in the antennal lobe, the primary olfactory neuropile in the insect brain, starts in late pupa and continues during the first days of adult life, at the same time as the behavioral response to odors matures. The antennal lobe is made up of functional units with a globular structure called the glomeruli, which can be recurrently identified due to their position and morphology. Individual olfactory glomeruli (DM6, DM2, and V) in Drosophila display specific growth patterns between days 1 and 12 of adult life. Experience can modify the olfactory pathway both structurally and functionally, as shown by adaptation experiments. The modifications associated with this form of learning seem to take place at a critical age. Exposure to benzaldehyde at days 2-5 of adult life, but not at $8-11$, causes behavioral adaptation as well as structural changes in DM2 and V glomeruli. Taken together, these data demonstrate an imprinting-like phenomenon in the olfactory pathway of young Drosophila adults, and illustrate its glomerulus-specific dynamics.

\subsubsection{Elemental Forms of Associative Learning}

Rapid changes in environmental contingencies require flexible capacities with which organisms can come to expect biologically significant events and modify their behavior in anticipation of those events if behavior is to remain adaptive; that is, increase the probability of obtaining beneficial consequences and avoiding harmful ones (Reif, 1998; Sutton and Barto, 1998; Dickinson and Balleine, 2002). The acquisition of such anticipatory behavior relies on simple associative principles.

These principles are centered on computing error signals: whenever the current expectation is violated, error signals trigger processes in the brain which serve to both keep the animal's expectation 
up-to-date and minimize such errors. The most potent error signals are generated by unexpected situations or events with biological relevance (i.e., an unconditioned stimulus, US): upon first perceiving such an unexpected US, coincidence detectors evaluate any neural activity preceding or overlapping with the error signal generated by the US. A priori it is irrelevant if this neural activity stems from the animal's behavior (abbreviated: $\mathrm{BH}$ ) and/or from any environmental stimulation (i.e., a conditioned stimulus, CS). The preceding events can serve as predictors of the US, if their temporal connection with the US is consistent enough. Depending on the state of the animal and the nature of the environment, several more encounters with the US and its preceding events are required for a reliable memory to form. A reliable memory means that fully expected USs no longer generate any error signals, and hence the animal does not need to update its expectations any further. In such a state, the animal can behave adaptively: it expects the consequences of any behavior or situation.

There are two basic ways in which such memories can be acquired. In operant (or instrumental) conditioning the behavior $(\mathrm{BH})$ of the animal is essential for these memories to form; indeed, it is the predictor by which the animal controls the occurrence of the US. If, on the other hand, the animal's behavior is dispensable for learning to occur, the situation is termed classical (or Pavlovian) conditioning. In freely moving animals, these two systems work together to guide adaptive behavior; Pavlovian learning often provides information to guide the selection of a particular behavioral strategy. But these systems can also work independently and even in opposition to one another (Ellison and Konorski, 1964; Balleine, 2001).

\subsubsection{Invertebrate Classical Conditioning}

The main associative principle for the conceptual understanding of classical conditioning is the notion of stimulus substitution (Pavlov, 1927). In the naïve animal, the CS initially triggers no or little response, that is, there is a transmission block from the sensory pathway to the motor circuits. If this CS is paired consistently enough with an initially unexpected US, the locations in the nervous system where the sensory information about the two events converge are modified such that the CS now comes to elicit a behavioral response, often mimicking the response to the US. The pairing has created new connections or removed transmission blocks so that the sensory circuitry processing the CS can now access some of the response-producing motor circuits that were previously engaged only by the US. By acquiring some of the response-eliciting properties of the US, the CS prepares the animal for the US and minimizes the error signals that future USs generate.

For instance, in Aplysia skin, sensory neurons make direct synapses onto motor neurons that control the defensive gill withdrawal reflex. Upon a light touch to the naïve animal's siphon, these sensorimotor synapses fail to conduct and the gills are not withdrawn. However, if the touch is repeatedly paired with a noxious stimulus (such as an electric shock) which does elicit gill withdrawal, the light touch alone eventually comes to elicit a gill withdrawal, whereas before such training it did not (see, e.g., Kandel et al., 1979, 1983; Walters et al., 1979, 1981; Carew et al., 1981, 1983, 1984; Kandel and Schwartz, 1982; Hawkins et al., 1983, 1986, 1989, 1998; Walters and Byrne, 1983a, 1983b; Abrams and Kandel, 1988; Byrne et al., 1990). This increase in synaptic efficacy (facilitation) is brought about by the action of the neuromodulator serotonin released by modulatory interneurons during the electric shock. The sea slug Aplysia was most helpful for identifying synaptic facilitation as an instance of stimulus substitution and thus establishing a neurobiological basis for a psychological concept.

The discovery of such simple biological processes was of tremendous importance for the study of classical conditioning in more complex invertebrate brains such as those of insects. This can be exemplified in olfactory learning. The similar structure of the first few processing stages of smell in vertebrates and invertebrates is intriguing. Sensory neurons expressing the same olfactory receptor converge on aggregates of glomerular neuropil structures, where they synapse onto local interneurons and projecting neurons. In both vertebrates and invertebrates the pattern of neural activity in the glomeruli is odor specific. In insects, the projection neurons transmit this pattern to the next synapse in the calyces of the mushroom bodies. Evidence from aversive conditioning in Drosophila and from appetitive conditioning in Apis points toward an initial CS conduction failure either at the input synapse, or the output synapse of the mushroom body Kenyon cells, or suggests additive effects at both (Heisenberg, 2003). In Drosophila, a group of animals is exposed to one of two initially equivalent odors at a time in a vial coated with an electried grid (e.g., Tully and Quinn, 1985; Tully, 1991; Tully et al., 1994). One of the odors is paired with an electric shock. After a few such odor-shock pairings, the animals are exposed to each of the odors 
from opposing vials in a decision chamber and have to make a choice between the odors. In a successful conditioning experiment, the large majority of flies will avoid the odor associated with the shock. In the honeybee, individually harnessed hungry animals initially rarely respond to an odor presentation with an extension of their mouthparts (proboscis), whereas they will almost invariably do so if a sugar solution touches their antennas (e.g., Menzel, 1990; Menzel and Müller, 1996). If the odor is paired with the sucrose stimulation even only once, a stable memory of this association is formed and the animal will exhibit the conditioned proboscis extension response (PER) to future presentations of the odor alone. In both insects, the information about the identity of the odors is relayed to the behavior-initiating centers deep in the brain via the glomerular olfactory lobes and the mushroom bodies. Neurons containing the neuromodulators octopamine and dopamine have been found which could modulate any of the synapses in this pathway (Hammer, 1993, 1997; Schwaerzel et al., 2003). Interestingly for the notion of expectation and anticipation, the octopaminergic neuron $\mathrm{VUM}_{\mathrm{mx} 1}$ exhibits activity paralleling the animal's expectation: it responds to unexpected sucrose presentations, but not to expected ones (Hammer, 1993, 1997). While there is evidence in vertebrates of how this reduction in the error signal may be implemented biologically, such evidence is still lacking in invertebrates. Conditioning using the PER has been so successful that it has been established in other insects such as moths and flies (Medioni and Vaysse, 1975; DeJianne et al., 1985; Holliday and Hirsch, 1986; Brigui et al., 1990; Fan et al., 1997; Fresquet, 1999; Hartlieb et al., 1999; Daly and Smith, 2000; Fan and Hansson, 2001; Skiri et al., 2005) and for use with mechanosensory stimuli (Giurfa and Malun, 2004).

There is another advantageous snail model system for predictive learning, the pond snail Lymnaea. Its feeding behavior can be classically and its respiratory behavior operantly conditioned. Appetitive classical conditioning of Lymnaea feeding behavior involves either a tactile (touch to the lips) or a chemical (amylacetate) CS and a sucrose US (Kemenes et al., 2002; Jones et al., 2003; Staras et al., 2003; Straub et al., 2004; Fulton et al., 2005; Korneev et al., 2005). A single presentation of either CS with a sucrose solution will enhance Lymnaea's bititing frequency in the presence of future CSs presented without the sucrose. Changes in neuronal activity and cellular properties that were recorded following tactile conditioning occur at all levels of the system, including central sensory pathways, modulatory interneurons, central pattern generator (CPG) interneurons, and motoneurons involving several possible plasticity sites. Aplysia biting behavior can be conditioned similarly (Lechner et al., $2000 \mathrm{a}, 2000 \mathrm{~b})$. A brief touch to the lips with a small brush (CS) does not usually elicit a bite. But when this touch is consistently paired with a food reward (US), the touch alone suffices to elicit the bite. This procedure has been transferred to a reduced preparation, where peripheral nerve stimulation replaces the CS and US and motor nerve recordings monitor the behavior (Mozzachiodi et al., 2003).

A third molluskan model system, the predatory snail Hermissenda, has revealed principal aspects of classical conditioning. The conditioning procedure consists of pairing light CS with high-speed rotation, or orbital shaking (US) which are aversive stimuli for the snail (Crow, 2004). Two responses are elicited by rotation, a reduced rate of forward locomotion and foot shortening. The two sensory structures mediating the CS and US are central, and thus their synaptic projections remain intact after isolation of the nervous system. Because the neurons that contribute to the neural circuitry controlling the unconditioned responses (URs) and conditioned responses (CRs) are identified, and can be studied in semi-intact nervous systems, an explanation is within reach of how conditioning is expressed in behavior generation.

Recently, earthworms have also been classically conditioned to anticipate potentially dangerous illumination after a brief vibration by longitudinally contracting their body (Watanabe et al., 2005). Other invertebrate model systems for classical conditioning include cockroaches and crickets (Matsumoto and Mizunami, 2002, 2004; Matsumoto et al., 2003; Watanabe et al., 2003; Kwon et al., 2004; Lent and Kwon, 2004; Pinter et al., 2005).

The notion of predictability and error signal minimization developed mainly from classical conditioning experiments. In the course of these experiments, a number of paradigms were developed which now can be used to probe invertebrate preparations for the biological substrate underlying these learning phenomena. The first hint at predictability at the chore of classical conditioning came from its strict dependence on the relative timing of CS and US. In order for classical conditioning to occur, the onset of the CS has to occur before the onset of the US. Simultaneous or reverse (backward) pairings yield very little to no learning (Hellstern et al., 1998). This result also contradicts the notion that simple pairings were sufficient for conditioning to occur. The next challenge to the simple pairing 
hypothesis was to randomly add US-alone presentations, so as to render the CS nonpredictive, but to preserve the total number of paired CS-US presentations from successful experiments. Strengthening the predictability hypothesis, a US that is presented equally often with or without the CS prevents any CS-US conditioning that would normally have occurred (Rescorla, 1968). More sophisticated experiments included a second CS. In sensory preconditioning (Brogden, 1939; Kimmel, 1977), CS1 and CS2 are first presented together, without any US. In a second training phase, one of them (CS1) is paired with the US until the CS1-US association is formed. In the test phase, CS2 is tested alone. Successful sensory preconditioning experiments also contradict the simple pairing hypothesis, since CS2 was never paired with the US (Brembs and Heisenberg, 2001; Guo and Guo, 2005; for the honeybee, Müller et al., 2000). In blocking experiments (Kamin, 1968), a first training phase consists of CS1-US pairings. In the second training phase, CS2 is added, so that the compound CS1-CS2 is paired with the US. The idea behind this experiment is that the prediction error signal for the US is zero after the first training phase (CS1 fully predicts every US occurrence) and as such nothing will be learned about the 'redundant' CS2. Hence the term 'blocking': the learning about CS1 blocks any learning about CS2, even though it was paired with the US sufficiently to produce classical conditioning had the first training not occurred (see Brembs and Heisenberg, 2001 for invertebrate literature on blocking). In the honeybee, the data on blocking are controversial (Smith and Cobey, 1994; Gerber and Ullrich, 1999). It is yet to be resolved whether the kind of odor stimulus (Linster and Smith, 1997) or the adequate control group will help to determine that blocking is a reliable phenomenon.

Perhaps not very surprisingly, all mechanisms and changes found to subserve classical conditioning in any of the above-mentioned model systems affect the CS pathway, emphasizing the universal role stimulus substitution plays in classical conditioning.

The relationship between classical conditioning procedures and predictive learning has often provided the justification for using this paradigm to study the neural bases of animals' basic cognitive or representational capacities. Nevertheless, it is rarely recognized that, at an adaptive level, cognitive capacities, such as those involved in encoding the predictive relations between stimuli, can be of little functional value to the purely Pavlovian organism. The sensitivity of cognitive systems to sources of information would seem more likely to provide the basis for modifying, even withholding or reversing, the direction of behavior in response to that information, something that demands greater behavioral flexibility than the system mediating classical conditioning provides. Hence, through developing an understanding of operant conditioning, one may actually come closer to establishing the functional role of cognitive processes in behavior.

\subsubsection{Invertebrate Operant Conditioning}

Just as in classical conditioning, error signals from unexpected events drive operant conditioning. The main associative principles using these signals are the concepts of initiating and gating behavioral activity. In the naïve animal, a behavior initially without a biologically relevant consequence is suddenly followed by the perception of an unexpected US. In sufficiently ambiguous situations, the animal has to first initiate a number of behavioral programs in order for the coincidence detectors to successfully cross-correlate this behavior with the novel US ('trying out'): any of its behaviors around the given time may have triggered the US. The significant cross-correlation between behavior and US eventually leads to modifications that act as a gate, letting only the behaviors pass that will maximize reward or minimize punishment (operant behavior). It is hypothesized that during operant conditioning separate processes modify the subsequent, more persistent initiation of behavior (operant memory). In contrast to classical conditioning, there is evidence from invertebrates on how the error signals may be generated in the brain. Whenever an action is initiated, a corollary discharge (or efference copy) is fed forward as a control signal to be compared with the sensory input. The difference between this control signal (expectation) and the actual sensory input generates the error signal (for a review, see Webb, 2004).

Isolating a behavior from any consequences other than a single biologically significant one (i.e., a US) is difficult. Hence, it is not surprising that there are only a few operant conditioning experiments which have demonstrated a reduction analogous to classical conditioning (one predictor - one consequence, $\mathrm{BH} \rightarrow \mathrm{US}$ ).

Drosophila suspended at the torque meter is probably as isolated from operant feedback as technically possible in an intact animal (Heisenberg et al., 2001). Glued at head and thorax to a copper wire hook, it is clamped to a device that measures the fly's yaw torque (yt) (i.e., the force the fly generates when it attempts to turn about its vertical axis). The animal is tethered completely motionless 
and its visual environment is entirely homogeneous (since the head is fixed). In such a constant stimulus situation the animal may beat it wings, move its legs, bend the abdomen, or extend the proboscis with no consequences at all. The experimenter may choose to make a biologically relevant stimulus (e.g., an unpleasant heat beam, US) contingent on one of the behaviors the animal generates. For the fly, it means that without any warning from the environment, temperatures suddenly rise to an unpleasant level. The animal has to find out how to switch the heat off. There is no way the animal can know that the experimenter coupled the heat with yt values that correspond roughly to, say, right turns. The animal has to find this correlation by trying out different behaviors until it finds the correct flight control maneuvers that eventually lead to more tolerable temperatures. This is a completely arbitrary situation in which the animal has to spontaneously produce a range of behaviors. This array of different motor outputs must then be cross-correlated with the sensory input. Only behaviors with significant cross-correlations are to be maintained (gating). In principle, such a gating mechanism is neurobiologically straightforward: the neurons generating the relevant behaviors are active when the neuromodulators signaling the heat on- and offset are being released. These neurons will be modified by activity-dependent plasticity to bias any future behavior toward the behaviors controlling the heat. Such a process has been found in a similarly isolated behavioral preparation, that is physiologically much more accessible, the operant conditioning of feeding behavior in Aplysia (Nargeot et al., 1997, 1999a, 1999b, 1999c; Brembs et al., 2002, 2004; Brembs, 2003a, 2003b). In this paradigm, spontaneous bites (or the corresponding neural patterns in the reduced preparation) are rewarded by dopamine-releasing nerve stimulation. A series of experiments suggests that dopamine-dependent modifications in the biophysical properties of a neuron that is active late during the rewarded behavior (and is critical for the type of behavior - biting) are partly responsible for the increased probability of emitting biting behavior in contingently reinforced animals as compared to control animals.

Thus, similar to classical conditioning, the psychological concept of behavior selection in operant conditioning could be related to a neurobiological mechanism.

However, it is more difficult to imagine the neurobiological mechanism which modifies behavior initiation during operant conditioning. After all, the initiation of the behavior may take place quite some time before the US is perceived and therefore the neurons initiating behavior may have been silent for any amount of time. At the time of this writing, there is only one hint as to whether behavior-initiating neurons actually are modified, but there is no data about any possible mechanisms by which such modification may occur. One is tempted to draw from the concept of the efference copy to hypothesize about how this gap may be closed. Efference copies are corollary discharges during behavior that allow the animal to discern self-motion from passive motion. The connection of this neural activity with the sensory organs and the motor circuits make efference copies suitable candidates for the memorization of potential consequences of their respective actions and thus the link between behavior selection and initiation (Webb, 2004).

While there is no data confirming or falsifying these speculations to date, there are more operant conditioning paradigms which may be helpful in understanding the biological implementation of cognitive concepts in invertebrates.

The honeybee antennae can be operantly conditioned to assume a certain posture (Kisch and Erber, 1999). In a more reduced preparation, the activity of the fast flagellum flexor muscle is recorded extracellularly from the scapus of the antenna (Erber et al., 2000). Whenever the muscle activity exceeds a defined reward threshold, the animal is rewarded with a drop of sucrose solution. After several US deliveries, the frequency of the muscle potentials increases significantly over the spontaneous frequency. The conditioned changes of frequency can be observed for $30 \mathrm{~min}$ after conditioning and do not occur in yoked controls, which were rewarded independent of nerve activity.

Aversive operant conditioning of Lymnaea's aerial respiratory behavior involves stimulating the animal's pneumostome when it surfaces and attempts to breathe (Lukowiak et al., 1996, 1998, 2000, 2003; Lukowiak and Syed, 1999; Spencer et al., 1999; Haney and Lukowiak, 2001; McComb et al., 2002, 2003; Sangha et al., 2002, 2003; Scheibenstock et al., 2002; Spencer et al., 2002). The stimulation is aversive, which leads to the animal closing the pneumostome and learning as training progresses to reduce its attempts to open the pneumostome. Instead of aerial respiration, the animals rely on cutaneous respiration for oxygen and hence it could be shown that the decrease in pneumostome openings was not due to a generally detrimental effect of the procedure. The neural network mediating the behavior is simple and well studied, making Lymnaea a very promising model system for the understanding of behavior initiation and selection. 


\subsubsection{Invertebrate Composite Operant Conditioning}

Of course, in freely moving animals, a CS rarely occurs independent of all the animal's behaviors, just as a US will very rarely be contingent on a behavior independent of any other stimulus present. Such situations (i.e., with a BH, a CS, and an US present) are called composite operant conditioning. Drosophila, Aplysia, and the honeybee are also the most widely used model systems for studying composite operant conditioning. Exploiting their unique technical advantages, one paradigm each in both Drosophila and Aplysia has been explicitly developed to combine operant and classical components in a single preparation. If one adds coloration of the (unpatterned) arena as a CS to the operant yaw torque learning paradigm described above for Drosophila, one creates an instance of composite operant conditioning (Heisenberg et al., 2001). Whenever the yaw torque of the fly is in one of the two domains (roughly corresponding to left or right turns, respectively), the arena surrounding the animal is illuminated in one color; if the yaw torque moves into the other domain, the coloration changes as well. Thus, yaw torque and color become equivalent predictors of the punishing heat. This switch (sw)-mode learning causes a larger aftereffect than yaw torque learning. This increased effectiveness of composite over purely operant or classical conditioning was observed previously, comparing classical conditioning to flight-simulator (fs) mode (Brembs and Heisenberg, 2000). In this setup, the angular velocity is calculated from the online torque signal that this momentum would give the fly. But instead of turning the fly, the yaw torque is made to turn the patterned arena around the fly in the opposite direction. This arrangement enables the fly to stabilize the arena, that is to fly straight with respect to the patterns on the arena wall, and to choose 'flight directions' with respect to these patterns. Before the training, the fly shows a moderate fixation of the patterns without a striking preference for one or the other. During training, the punishing heat beam is applied whenever the fly chooses a flight direction toward one of the pattern types. If after a few minutes of training the heat is permanently switched off the fly still prefers flight directions toward the previously 'cold' patterns.

Is visual pattern discrimination learning operant? The fly learns to associate the patterns (CS) with heat and 'no-heat' (US), meeting the definition of classical (Pavlovian) conditioning. Could the operant behavior in fs-learning merely accompany a learning process which in essence is classical? The standard experiment to answer this question is a 'yoked' control (Brembs and Heisenberg, 2000). Exact sequences of pattern position and heating periods are recorded during operant training and are played back to a naïve fly. The replay control is a purely classical conditioning experiment, since the fly has no influence on the stimuli presentation. This kind of training is considerably less effective than the training operantly controlled by the fly. Thus, just as the sw-mode learning is more effective than the yt-learning, the training in fs-learning is more effective than in replay control. In other words, in both cases the three-term contingency $(\mathrm{CS} \rightarrow \mathrm{US}, \mathrm{BH} \rightarrow \mathrm{US})$ is more efficient than the two-term contingency ( $\mathrm{BH} \rightarrow \mathrm{US}$ in yt-learning; $\mathrm{CS} \rightarrow$ US in the yoked control of fs-learning). The interesting difference is that in fs-learning the behavior is not directly modified (Brembs and Heisenberg, 2000), whereas in sw-learning the spontaneous yt-distribution is altered just as in ytlearning. This allowed investigating which of the components are learned in the three-term contingency (Heisenberg et al., 2001). These studies showed that in both fs- and sw-learning only the classical but not the operant association is separately accessible, ruling out that the two act additively. Not summation but rather interaction between the operant and classical components characterizes the three-term contingency. Apparently, composite conditioning is so effective because learning about sensory stimuli is enhanced once the fly can control them by its own behavior, whereas behavioral modifications tend to be avoided (Heisenberg et al., 2001). Experiments with robots have yielded similar results, supporting the notion of a general synergistic mechanism (Verschure et al., 2003).

Similar questions can now be asked in a newly developed preparation in Aplysia. It was described above how the feeding behavior of Aplysia can be conditioned classically and operantly (Nargeot et al., 1997, 1999a, 1999b, 1999c; Lechner et al., 2000a, 2000b; Brembs et al., 2002, 2004; Brembs, 2003a, 2003b; Mozzachiodi et al., 2003). Taking advantage of the greater physiological accessibility, a reduced preparation of the isolated buccal and cerebral ganglia was used. This preparation still produces spontaneous nervous activity, which can be recorded as patterned motor output at selected motor nerves. These neuronal patterns can be related to feeding behavior in the intact animal. Stimulation of sensory nerves serves as CS and US input. Thus, all elements of the three-term contingency are present: $\mathrm{BH}, \mathrm{CS}$, and US. The preparation has been shown to produce robust learning effects; it 
will be interesting to see if results can be found that are analogous to those in Drosophila and, if so, what their neural basis is (Brembs et al., 2004).

Susswein and colleagues have developed another promising composite paradigm using Aplysia feeding behavior (Susswein and Schwarz, 1983; Schwarz and Susswein, 1984, 1986, 1992; Susswein et al., 1986; Schwarz et al., 1991; Chiel and Susswein, 1993; Botzer et al., 1998; Katzoff et al., 2002). Food touching the lips of Aplysia initiates biting, which causes food to enter the mouth. Swallowing is triggered by food within the mouth. Food or nonfood objects in the mouth can also trigger rejection (Kupfermann, 1974). In this aversive procedure, animals learn to avoid biting on inedible food items. Food is made inedible by wrapping it in a plastic net that the animals can neither swallow nor break. During training, the netted food touches the lips and the animal tastes the food through holes in the net. The animal bites, food enters the mouth and elicits swallows, which fail to convey the tough food to the gut. The food eventually is rejected. The food continues to stimulate the lips and elicit bites, which again lead to failed swallows. As training proceeds, the response of the animal to the food gradually changes. Food stays within the mouth for progressively shorter periods, eliciting fewer swallows and more rejections. Animals eventually stop responding to the food (Susswein et al., 1986).

An instrument more suitable than the fs for using the powerful genetic techniques in Drosophila for operant conditioning is the heat box (Wustmann et al., 1996; Wustmann and Heisenberg, 1997; Putz and Heisenberg, 2002). In the tiny, dark chamber, every time the fly walks into a designated half, the whole chamber is heated. As soon as the animal leaves the punished half, the chamber temperature reverts to normal. Even if the heat is switched off after a few minutes, the animals still restrict their movements to only one half of the chamber. Because it is completely dark in the chamber, the animal most likely relies on idiothetic cues to orient itself, thus minimizing the contamination with potential classical predictors. It can be shown that the operant memory consists of two components, a spatial component and a "stay-where-you-are" component (Putz and Heisenberg, 2002). One of the mutants found using the heat box is the 'ignorant' gene (Putz, 2003; Putz et al., 2004). Interestingly, it appears that 'ignorant' has very different effects on operant and classical conditioning. The original mutant allele (ignP1) shows a sexual dimorphism in the heat box, where males are impaired but females appear normal (Putz, 2003; Putz et al., 2004).
Both males and females of that line are statistically indistinguishable from the wild-type controls in olfactory classical conditioning (Bertolucci, 2003). The null mutant $\left(\right.$ ign $^{58 / 1}$ ) shows decreased learning and memory in the classical case (Bertolucci, 2003), but is normal in the heat box (Putz, 2003; Putz et al., 2004). Finally, several partial deletions of the ignorant gene are defective in the heat box (Putz, 2003; Putz et al., 2004), but these lines have not yet been tested for classical conditioning. Apparently, different mutations of the 'ignorant' gene have different effects on operant and classical conditioning, indicating fairly well-separated mechanisms for both forms of learning.

Another composite paradigm in honeybees and bumblebees is visual discrimination learning in the Y-maze. The freely flying bees enter a triangular decision chamber on one side and can see two target objects at the ends of the two arms of the ' $\mathrm{Y}$ ' attached to the other two sides of the triangular chamber. Only one of the two targets contains a sucrose reward and thus animals can be trained to associate one of the two targets with the reward. Repeating the procedure with the targets at both arms in random sequence establishes a visual discrimination memory that is independent of the location of the target and hence of the turning maneuvers needed to reach it. In this situation, bees learn to associate a given target with reward and the alternative target with the absence of reward such that the former is excitatory and the latter inhibitory (Giurfa et al., 1999). Furthermore, bees are rewarded for every correct choice such that operant and classical associations certainly drive their choice within the maze. Several variants are known of this kind of visual learning in bees: from the simple visual target conditioning in which a bee has to land on a single rewarded stimulus, to training with a complex maze made from several connected boxes, at the end of which they get rewarded with sucrose solution (Zhang et al., 1999), bees efficiently learn this kind of task which has allowed further insights into higher-order forms of learning (see Section 1.26.4).

\subsubsection{Nonelemental Forms of Associative Learning}

In previous sections we reviewed different forms of associative learning that can be described as elemental forms of learning. These forms have in common that they can be formalized as links that connect specific stimuli (in the case of Pavlovian conditioning), or a stimulus and a response (in the case of 
operant conditioning). In most of the paradigms described, such links are established in such a way that they connect directly and unambiguously welldefined events in the animal's environment (Rescorla and Wagner, 1972). Simple links between an event $(\mathrm{A}$ or $\mathrm{B}$ ) and reinforcement $(+)$ (or its absence: -) allow solving elemental problems such as absolute conditioning $(\mathrm{A}+)$ and differential conditioning $(\mathrm{A}+\mathrm{vs} . \mathrm{B}-)$. In the former, an animal has to learn to respond to $\mathrm{A}$, which is unambiguously associated with reinforcement; in the latter, it has to learn to respond to $\mathrm{A}$ and not to $\mathrm{B}$ because $\mathrm{A}$ is unambiguously associated with reinforcement and $\mathrm{B}$ is unambiguously associated with the absence of reinforcement.

However, invertebrates are also capable of more complex forms of associative learning, which can be described as nonelemental forms of learning, and which in contraposition to elemental ones, do not rely on simple links between events. In the study of nonelemental learning, paradigms have been developed for which the associative strength of a specific event, stimulus or reaction, is ambiguous and therefore cannot be predictive for solving a problem. Such problems cannot be formalized, therefore, in terms of simple connectivity between events and their respective outcomes, because one or various events involved in the problem usually allow opposed outcomes (Pearce, 1994). For example: if a given stimulus, $\mathrm{A}$, is rewarded as often as not rewarded, and the key for solving the problem is that it is rewarded whenever it is presented together with a different stimulus $\mathrm{B}$, whereas it is nonrewarded when presented together with a third stimulus $\mathrm{C}(\mathrm{AB}+$ vs. $\mathrm{AC}-)$, the animal cannot rely on the pure associative strength of $\mathrm{A}$ to solve the problem. Two possibilities appear: (1) the nonelemental one, in which the animal learns that it is the configuration $(\mathrm{AB}$ or $\mathrm{AC})$ which counts and which has to be learned, independent of the associative strength of the elemental stimuli A, B, C; and (2) the elemental one in which the animal learns to focus on $\mathrm{B}$, which is always rewarded, and/or on C, which is always nonrewarded. This example, and its two possible interpretations which differ drastically, show that in studying whether animals exhibit nonelemental forms of learning, experiments must be carefully designed in order to avoid dual interpretations for the same behavioral outcome.

Standard paradigms have been developed by experimental psychologists to address this problem in an efficient manner (Rudy and Sutherland, 1992, 1995). Simple links between a stimulus and reinforcement do not allow solving nonelemental problems like negative patterning, biconditional discrimination, and the neutral discrimination feature (see discussion below). In these problems, each stimulus appears rewarded as often as nonrewarded such that linear solutions do not apply. In negative patterning, for instance, the subject has to learn to respond to the single stimuli $\mathrm{A}$ and $\mathrm{B}$ but not to their compound $\mathrm{AB}(\mathrm{A}+, \mathrm{B}+, \mathrm{AB}-)$. This problem does not admit elemental solutions, since the animals learn that $\mathrm{AB}$ has to be different from the linear sum of $\mathrm{A}$ and $\mathrm{B}$. In biconditional discrimination, the subject has to learn to respond to the compounds $\mathrm{AB}$ and $\mathrm{CD}$ and not to the compounds $\mathrm{AC}$ and $\mathrm{BD}(\mathrm{AB}+, \mathrm{CD}+$, $\mathrm{AC}-, \mathrm{BD}-)$. As in the previous problem, each element A, B, C, or D appears rewarded as often as nonrewarded such that it is impossible to rely on the associative strength of a given stimulus to solve the task. Finally, in feature neutral discrimination, the animal has to learn to respond to $\mathrm{B}$ and to the compound $\mathrm{AC}$ but not to $\mathrm{C}$ and the compound $\mathrm{AB}$ $(\mathrm{B}+, \mathrm{AC}+, \mathrm{C}-, \mathrm{AB}-)$. In this case, each element is again ambiguous such that the animal has to learn the predictive value of the compounds $\mathrm{AB}$ and $\mathrm{AC}$, independent of its composing elements, and the fact that $\mathrm{B}$ and $\mathrm{C}$ alone produce different outcomes than when in compound. These examples show to which extent more elaborated computational strategies are necessary in the case of nonelemental discrimination problems. In Section 1.26.6, other elaborated forms of nonelemental learning are discussed such as contextual learning, or rule learning, but here we focus on more formalized problems such as the ones just introduced, which allow discerning between linear and nonlinear problem solving. This distinction is pertinent not only with respect to the nature of established associations, but also with respect to the neural substrate subtending these different forms of learning (Rudy and Sutherland, 1995; Sutherland and Rudy, 1989). It has been suggested that different neuronal circuits and structures underlie elemental versus nonelemental learning in vertebrates, with a particular role assigned to the hippocampus and the cortical circuitry associated to it in the formation of nonelemental stimulus representations (Lachnit et al., 2004; Rudy and Sutherland, 1995).

Lobsters placed in an aquarium can be aversively conditioned to stop searching in it by pairing an olfactory stimulus delivered in water with a mechanosensory disturbance produced by the experimenter (Livermore et al., 1997). Lobsters were trained in this way with an olfactory compound $\mathrm{AX}$ reinforced $(\mathrm{AX}+)$. Conditioning was either absolute $(\mathrm{AX}+)$ or differential $(\mathrm{AX}+\mathrm{vs.}$ AY-). Both conditioning procedures yielded different results, thus showing that depending on the 
conditioning schedule, lobsters treated and learned the compound differently (Livermore et al., 1997). After absolute conditioning, lobsters inhibited their searching behavior when presented with AX but still searched when presented with $\mathrm{A}, \mathrm{X}$ or with a novel odor Y. Similarly, a novel compound AY did not inhibit searching behavior. This result is consistent with learning the compound AX as an entity different from its components A and X (the configural view; Pearce, 1994). After differential conditioning, lobsters inhibited their searching behavior when presented with AX but not with AY. Interestingly, they also inhibited search when presented with the element $\mathrm{X}$ but not with the element Y. A was not useful as it was common to the reinforced and the nonreinforced compounds AX+ and AY-, respectively (Livermore et al., 1997). In this case, lobsters seem to have learned the compounds AX and AY in elemental terms, thus being able to fully generalize their respective responses to $\mathrm{X}$ and $\mathrm{Y}$.

In the honeybee, several recent studies have addressed the issue of elemental versus nonelemental learning, using visual training of free-flying animals or olfactory conditioning of harnessed animals. In both modalities, bees are able to solve a biconditional discrimination $(\mathrm{AB}+, \mathrm{CD}+, \mathrm{AC}-$, BD-) - visual (Schubert et al., 2005); olfactory (Chandra and Smith, 1998; Hellstern et al., 1995). This capacity demonstrates that both visual and olfactory compounds are learned under certain circumstances as entities different from the simple sum of their elements. Similarly, negative patterning experiments $(\mathrm{A}+, \mathrm{B}+, \mathrm{AB}-)$ have also been performed both in the visual (Schubert et al., 2005) and the olfactory modality (Deisig et al., 2001, 2002). Such discrimination can only be explained if the compound $\mathrm{AB}$ is treated as being different from the simple sum of its elements. Two essential theories can be invoked for explaining this result; both are different from a purely linear approach based solely on the elements of a compound: the configural theory, mentioned above, which proposes that a mixture constitutes an entity different from its components $(\mathrm{AB}=\mathrm{X} \neq \mathrm{A}+\mathrm{B}$ ) (Pearce, 1994); and the unique-cue theory, which proposes that a mixture is processed as the lineal sum of its components plus a stimulus $(\mathrm{u})$ that is unique to the joint presentation of the elements in the mixture $(\mathrm{AB}=\mathrm{A}+\mathrm{B}+\mathrm{u})$ (Whitlow and Wagner, 1972). In the latter case, the unique cue supports the inhibitory strength assigned to the compound. In the case of honeybee olfactory learning, computer simulations and experiments such as negative patterning and its variants (Deisig et al., 2001, 2002, 2003) showed that olfactory compound learning and processing in bees was consistent with the uniquecue theory. A unique cue is generated when bees receive olfactory input to both brain sides, since bilateral olfactory input is required to solve a negative patterning task (Komischke et al., 2003). Assuming that the elements interfered with each other is implied in a modified unique-cue theory (Redhead and Pearce, 1995), which provided the best account for all the behavioral results available (Deisig et al., 2003; Lachnit et al., 2004).

Another paradigm used to study nonelemental olfactory learning in bees is the side-specific olfactory conditioning (Sandoz and Menzel, 2001). In this case, a thin plastic wall separates the honeybee's antennas during olfactory stimulation. Bees were differentially conditioned using two odors: A and $\mathrm{B}$. Bees were conditioned with $\mathrm{A}+$ versus $\mathrm{B}-$ on one antenna and with $\mathrm{A}-$ versus $\mathrm{B}+$ on the other. This discrimination resembles a form of contextual learning (see next section), since the context of each antennal side (left vs. right) determines the contingency of the stimuli. Bees learned to respond appropriately to the rewarded odor and to inhibit their reaction to the nonrewarded odor on each side (Sandoz and Menzel, 2001). They thus solved this side-specific, nonelemental discrimination.

This and two other paradigms were recently used to test mushroom body (MB)-ablated honeybees and to determine whether intact MBs are necessary to solve nonelemental olfactory discriminations (Komischke et al., 2005). Bees with unilateral lesions of the MBs generated by larval treatment with hydroxyurea (Malun, 1998) were trained under different olfactory conditioning designs. When odorants were delivered in a sidespecific manner, bees with unilateral MB lesions could not solve an unambiguous double discrimination (paradigm 1: $\mathrm{A}+, \mathrm{B}-$ on one antenna, $\mathrm{C}+$, $\mathrm{D}-$ on the other; $\mathrm{A}+\mathrm{B}-/ \mathrm{C}+\mathrm{D}-$ ), whereas they could solve at least one of both discriminations of an ambiguous problem (paradigm 2: $\mathrm{A}+, \mathrm{B}-$ on one antenna, $\mathrm{A}-, \mathrm{B}+$ on the other; $\mathrm{A}+\mathrm{B}-1$ $\mathrm{A}-\mathrm{B}+)$. In the latter case, they solved the discrimination proposed to their intact brain side. Nonablated bees could learn both side-specific discriminations. When odorants were delivered simultaneously to both antennas (paradigm 3: $\mathrm{A}+\mathrm{B}-\mathrm{C}+\mathrm{D}-)$, ablated bees learned slower than normal bees. Thus, in all three cases, the unilateral loss of a median calyx affected olfactory learning (Komischke et al., 2005). It was proposed that $\mathrm{MBs}$ are required for solving elemental olfactory tasks whose complexity is enhanced by virtue of the number of stimuli involved (paradigms 1 
and 3: four stimuli) and that $M B$ ablations could have an effect on the inhibition of information exchange between brain hemispheres. This exchange may or may not occur in normal circumstances, depending on the information stored in each brain side. MB lesions would impede the ablated side to block the transfer of information from the intact side in the side-specific ambiguous problem (paradigm 2).

Interestingly, cumulative experience seems to play a critical role for adopting elemental or nonelemental learning strategies (Giurfa et al., 2003). Giurfa et al. (2003) trained free-flying bees to fly into a Y-maze to collect sucrose solution on a rewarded stimulus presented in one of the arms of the maze. Stimuli were color disks, violet $(\mathrm{V})$, green $(\mathrm{G})$, or yellow $(\mathrm{Y})$, which were of equal perceptual salience for honeybees. Training followed an $\mathrm{A}+$, $\mathrm{BC}+$ design, followed by an $\mathrm{AC}$ versus $\mathrm{BC}$ test. Training consisted of $6(3 \mathrm{~A}+$ and $3 \mathrm{BC}+), 20(10$ $\mathrm{A}+$ and $10 \mathrm{BC}+)$, or $40(20 \mathrm{~A}+$ and $20 \mathrm{BC}+)$ acquisition trials. Elemental models of compound processing predict that in the test, a preference for the nontrained stimulus AC should occur while configural models predict a preference for the trained stimulus BC. After six training trials, bees favored an elemental strategy and preferred AC to $\mathrm{BC}$ during the tests. Increasing the number of training trials resulted in an increase of the choice of BC. Thus, short training favored processing the compound as the sum of its elements (elemental account) while long training favored its processing as being different from the sum of its elements (configural account). Additionally, it was observed that the change in stimulus processing was also influenced by stimulus similarity. Color perceptual similarity favored configural processing with increasing experience (Giurfa et al., 2003), a result that was consistent with the results of honeybee olfactory compound conditioning (Deisig et al., 2002).

It thus seems that some invertebrates, at least lobsters and honeybees, are capable of nonelemental forms of learning in the strict sense, and that such forms of learning are highly dependent on the way in which animals are trained, on the number of trials, and on the similarity between elements in a compound. Further factors favoring nonelemental compound processing and learning could be the spatial and temporal proximity of elements and the animals' previous experience. Further research should ask whether or not other invertebrate models can solve such nonlinear discrimination problems and determine the kind of processing underlying this problem solving.

\subsubsection{Integration Across Sensory Modalities and Rule Learning}

Animals, including invertebrates, can sometimes respond to novel stimuli that they have never before encountered or can generate novel responses that are adaptive given the context in which they are produced. In doing this, the animals exhibit a positive transfer of learning (Robertson, 2001), a capacity that cannot be referred to as an elemental form of learning because the responses are aimed toward stimuli that do not predict a specific outcome per se based on the animals' past experience. Moreover, animals can also learn to inhibit such a transfer in order to produce adaptive responses that can be linked to a specific context. They learn that, given a certain stimulus or condition, a particular response is appropriate, whereas, given a different stimulus or condition, the same response is no longer appropriate. This form of learning, usually referred as conditional learning or occasion setting, cannot be viewed as elemental learning, since a given stimulus may or not be predictive of a certain outcome, depending on the particular environment. Relying on its elemental outcome alone therefore does not help solving this kind of problem. In this section, we focus on these forms of nonelemental learning. We therefore deal with three main capacities: (1) selective attention, (2) rule learning, and (3) contextual learning. We start with selective attention, as it seems to be a necessary requisite for extracting the information that allows solving the other two problems.

\subsubsection{Selective Attention}

Selective attention consists of the ability to focus perceptual mechanisms on a particular stimulus and to actively process this information while ignoring nonrelevant stimuli (Zentall, 2005). It implies that the representation of the stimulus has been filtered or modified, presumably so that it can be processed or responded to more efficiently. Different approaches have been proposed to the notion of selective attention. Here we focus on the ecological notion of 'search image' (Tinbergen, 1960) and on the more traditional approach of discriminative learning to selective attention (Zentall and Riley, 2000).

Selective attention could be related to the notion of search image, since such images are assumed to exist in cruising animals in order to facilitate detection of relevant stimuli in the environment. Search images, which could be innate (see Section 1.26.2) or acquired through experience in the field, have been proposed to be a specific means for filtering 
out sensory information and focusing perception on specific stimulus configurations as a way to more efficiently forage and avoid predation. Innate search images driving the first foraging flights are assumed in insect pollinators, in order to facilitate the detection of flower sources (Menzel, 1985). Indeed, naïve bees exhibit innate preferences for biologically relevant floral cues such as colors (Giurfa et al., 1995; Gumbert, 2000) or bilateral symmetry (Rodriguez et al., 2004). Salticid spiders have also an innate predisposition to form search images for preferred preys (spiders) rather than for nonpreferred preys (insects) (Jackson and Li, 2004).

Traditionally, selective attention has been studied through a discriminative learning approach. Such an approach posits that through selective attention animals gradually learn to attend to the dimension along which discriminative stimuli differ (Mackintosh, 1975). Honeybees (Giurfa, 2004) and bumblebees (Dyer and Chittka, 2004) discriminate differently a given color after absolute (training with a single reinforced color) and differential conditioning (training with a reinforced color and nonreinforced alternatives). They become progressively better in discriminating the trained color from colors that are perceptually close after prolonged differential conditioning while they are incapable of such discrimination after the same amount of absolute conditioning These results can be interpreted along the selective attention hypothesis such that insects gradually learned to attend to the spectral dimension along which discriminative stimuli differed. An alternative interpretation posits that differentially conditioned animals form positive and negative generalization gradients to the rewarded and the unrewarded stimulus, respectively, and thus develop a sharper generalization profile for the learned stimulus. An attentional account may also apply to pattern discrimination experiments in which bees do or do not discriminate the same two patterns depending on the kind of training used, absolute or differential conditioning (Giurfa et al., 1999). Absolute conditioning promoted recognition based on local cues (the lower half of a disk made of different sectors) while differential conditioning expanded it to the whole pattern.

Arguments in favor of selective attention in invertebrates come from research on the fruit fly D. melanogaster (van Swinderen and Greenspan, 2003). A fly flying stationary within a circular arena and tracking a visual moving object (a vertical black bar) exhibits behavioral and neural processes consistent with selective attention for visual stimuli. Local field potentials recorded in the central brain of these flies show that activity in the $20-30 \mathrm{~Hz}$ range increases as a response to the moving bar when it appears in the visual field of the fly and before the insect initiates tracking. This neural response, which is interpreted as being related to the perceptual event occurring at the onset of stimulus tracking, can be retraced to the mushroom bodies. It increases by novelty and odor-evoked salience, it is anticipatory, and it is reduced when the fly is in a sleep-like state. These results suggest that selective attention underlies visual tracking in flies.

\subsubsection{Rule Learning}

Selective attention constitutes the very basis of rule learning, because in such a process animals learn to focus attention on the relevant information that allows detecting the rule underlying the problem to be solved. Rule learning presupposes positive transfer of an appropriate response from a known set to a novel set of stimuli. In this case, the animal bases its choice not on the perceptual similarity between the novel and the known stimuli, which might not share any common feature, but on a rule which transcends the stimuli used to train it. Examples of such rules are 'larger than', or 'on top of', which may apply to stimuli which do not share any common feature but which can nevertheless be classified according to the rule. Other examples are the so-called principles of sameness and of difference. These rules are uncovered through delayed matching to sample (DMTS) and the delayed nonmatching to sample (DNMTS) experiments, respectively. In DMTS, animals are presented with a sample and then with a set of stimuli, one of which is identical to the sample and which is reinforced. Since the sample is regularly changed, they must learn the sameness rule 'always choose what is shown to you (the sample), independent of what else is shown to you'. In DNMTS, the animal has to learn the opposite, that is 'always choose the opposite of what is shown to you (the sample)'.

Honeybees foraging in a Y-maze learn both rules (Giurfa et al., 2001). Bees were trained in a DMTS problem in which they were presented with a changing nonrewarded sample (i.e., one of two different color disks or one of two different black-and-white gratings, vertical or horizontal) at the entrance of a maze. The bees were rewarded only if they chose the stimulus identical to the sample once within the maze. Bees trained with colors and presented in transfer tests with gratings that they have not experienced before solved the problem and chose the grating identical to the sample at the entrance of the maze. Similarly, bees trained with the gratings 
and tested with colors in transfer tests also solved the problem and chose the novel color corresponding to that of the sample grating at the maze entrance. Transfer was not limited to different kinds of modalities (pattern vs. color) within the visual domain, but could also operate between drastically different domains such as olfaction and vision (Giurfa et al., 2001). Furthermore, bees also mastered a DNMTS task, thus showing that they also learned a principle of difference between stimuli (Giurfa et al., 2001). These results document that bees learn rules relating stimuli in their environment. The capacity of honeybees to solve DMTS tasks has recently been verified (Zhang et al., 2004, 2005). It was found that the working memory for the sample underlying the solving of DMTS is $\sim 5 \mathrm{~s}$ (Zhang et al., 2005) and thus coincides with the duration of other visual and olfactory short-term memories characterized in simpler forms of associative learning in honeybees (see Section 1.26.6). Moreover, bees trained in a DMTS task can learn to pay attention to one of two different samples presented successively in a flight tunnel (either to the first or to the second) and can transfer the learning of this sequence weight to novel samples (Zhang et al., 2005).

Despite the honeybees' evident capacity to solve relational problems such as the DMTS or the DNMTS tasks, such capacities are not unlimited. In some cases, biological constraints may impede the solving of a particular problem for which rule extraction is necessary. It is therefore interesting to focus on a different example of rule learning which bees could not master, the transitive inference problem (Benard and Giurfa, 2004). In this problem, animals have to learn a transitive rule, that is, $\mathrm{A}>\mathrm{B}, \mathrm{B}>\mathrm{C}$, then $\mathrm{A}>\mathrm{C}$. Preference for A over $\mathrm{C}$ in this context can be explained by two strategies: (1) deductive reasoning (Fersen et al., 1990) in which the experimental subjects construct and manipulate a unitary and linear representation of the implicit hierarchy $\mathrm{A}>\mathrm{B}>\mathrm{C}$; or (2) responding as a function of reinforced and not reinforced experiences (Terrace and McGonigle, 1994), in which case animals choose among stimuli based on their associative strength, that is, on the effective number of reinforced and nonreinforced experiences with the stimuli.

To determine whether bees learn the transitive rule, they were trained using five different visual stimuli $\mathrm{A}, \mathrm{B}, \mathrm{C}, \mathrm{D}$, and $\mathrm{E}$ in a multiple discrimination task $\mathrm{A}+$ versus $\mathrm{B}-, \mathrm{B}+$ versus $\mathrm{C}-, \mathrm{C}+$ versus $\mathrm{D}-$, and $\mathrm{D}+$ versus $\mathrm{E}-$ (Benard and Giurfa, 2004). Training therefore involved overlapping of adjacent premise pairs $(\mathrm{A}>\mathrm{B}, \mathrm{B}>\mathrm{C}, \mathrm{C}>\mathrm{D}, \mathrm{D}>\mathrm{E})$, which underlie a linear hierarchy $\mathrm{A}>\mathrm{B}>\mathrm{C}>\mathrm{D}>\mathrm{E}$. After training, bees were tested with $B$ versus $D$, a nonadjacent pair of stimuli that were never explicitly trained together. In theory, B and D have equivalent associative strengths because they are, in principle, equally associated with reinforcement or absence of it during training. Thus, if bees were guided by the stimulus' associative strength, they should choose randomly between $\mathrm{B}$ and D. If, however, bees used a transitive rule, they should prefer B to D.

Honeybees learned the premise pairs as long as these were trained as uninterrupted, consecutive blocks of trials (Benard and Giurfa, 2004). But if shorter and interspersed blocks of trials were used, such that bees had to master all pairs practically simultaneously, performance collapsed and bees did not learn the premise pairs. The bees' choice was significantly influenced by their experience with the last pair of stimuli $(\mathrm{D}+\mathrm{vs}$. $\mathrm{E}-)$ such that they preferred $\mathrm{D}$ and avoided $\mathrm{E}$. In the tests, no preference for $\mathrm{B}$ to $\mathrm{D}$ was found. Although this result agrees with an evaluation of stimuli in terms of their associative strength (see above), during training bees visited more $\mathrm{B}$ when it was rewarding than $\mathrm{D}$, such that a preference for $\mathrm{B}$ should have been expected if only the associative strength were guiding the bees' choices. It was then concluded that bees do not establish transitive inferences between stimuli but rather guide their choices by the joint action of a recency effect (preference of the last rewarded stimulus, D) and by an evaluation of the associative strength of the stimuli (in which case preference for B should be evident). As the former supports choice of $\mathrm{D}$ while the latter supports choice of $B$, equal choice of $B$ and $D$ in the tests could be explained (Benard and Giurfa, 2004). In any case, memory constraints (in this case the fact that simultaneous mastering of the different premise pairs was not possible and the fact that the last excitatory memory seems to predominate over previous memories) impeded learning the transitive rule.

\subsubsection{Conditional Discriminations: Occasion Setting and Contextual Learning}

Contextual learning is a term widely used for describing conditional discriminations which can be subsumed in the so-called occasion setting problem (Schmajuk and Holland, 1998). In this problem, a given stimulus, the occasion setter, informs the animal about the outcome of its choice (for instance, given stimulus $\mathrm{C}$, the occasion setter, the animal has to choose $\mathrm{A}$ and not $\mathrm{B}$ because the former but not the latter is rewarded). This basic 
form of conditional learning admits different variants depending on the number of occasion setters and discriminations involved, which have received different names. For instance, another form of occasion setting involving two occasion setters is the socalled transwitching problem. In this problem, an animal is trained differentially with two stimuli, A and $\mathrm{B}$, and with two different occasion setters, C1 and $\mathrm{C} 2$. When $\mathrm{C} 1$ is available, stimulus $\mathrm{A}$ is rewarded while stimulus $\mathrm{B}$ is not $(\mathrm{A}+\mathrm{vs} . \mathrm{B}-)$, while it is the opposite $(\mathrm{A}-$ vs. $\mathrm{B}+$ ) with $\mathrm{C} 2$. Focusing on the elements alone does not allow solving the problem as each element $(\mathrm{A}, \mathrm{B})$ appears equally as often rewarded and nonrewarded. Each occasion setter $(\mathrm{C} 1, \mathrm{C} 2)$ is, in the same way, simultaneously rewarded and nonrewarded, depending on its association with A or B. Animals have, therefore, to learn that $\mathrm{C} 1$ and $\mathrm{C} 2$ define the valid contingency. The transwitching problem is considered a form of contextual learning because the occasion setters C1 and C2 can be viewed as contexts determining the appropriateness of each choice. Note that a problem like the biconditional discrimination $(\mathrm{AB}+, \mathrm{CD}+, \mathrm{BC}-, \mathrm{AD}-$; see Section 1.26.4) is amenable to a transwitching problem, and thus to an occasion-setting problem, if one assumes that $\mathrm{A}$ and $\mathrm{C}$ act as occasion setters for $\mathrm{B}$ and $\mathrm{D}$ (i.e., given $\mathrm{A}, \mathrm{B}+$ vs. $\mathrm{D}-$, and given $\mathrm{C}, \mathrm{B}-$ vs. $\mathrm{D}+$ ). This is so because all these problems are forms of conditional learning in which a stimulus can have different associates depending on the conditions in which it is presented.

Despite semantic confusions, conditional discriminations viewed as contextual learning have been studied in several invertebrate models. We will keep the term 'contextual learning' as it appears recurrently in the works that we will discuss from here on. In the nematode Caenorhabditis elegans, retention of habituation of an escape response is aided by contextual associations formed during training (Rankin, 2000; see also Section 1.26.6). Nematodes were trained and tested in the presence of a chemosensory cue $\left(\mathrm{NaCH}_{3} \mathrm{COO}\right)$ which was used as the general context surrounding the animals. Animals trained and tested in different chemosensory environments showed lower retention than animals that stayed in the same context. In the same animal, Law et al. (2004) used taste cues to create distinct contexts for olfactory adaptation assays and showed that performance in this associative learning paradigm is sensitive to context manipulations. In Aplysia californica, Colwill et al. (1988) showed that animals exposed to two different contexts, a smooth, round bowl containing lemon-flavored seawater and a rectangular chamber with a ridged surface containing unscented seawater that was gently vibrated by an aerator located in one corner, and receiving a series of moderate electric shocks (US) in one of these two contexts, established an association between the context and the shock. The context alone elicited a defensive reaction which was exclusive for the reinforced context. In the freshwater pond snail Lymnaea stagnalis, aerial respiratory behavior was operantly conditioned so that the animals performed aerial respiration significantly less often (Lukowiak et al., 1996; see also Section 1.26.3). Recall of the learned behavior was dependent on the context in which memory was established. Animals trained in water containing food odorant (the contextual cue) exhibited recall only in the presence of such food odorant context (Haney and Lukowiak, 2001).

Arthropods have provided reliable evidence of contextual learning. Hermitte et al. (1999) found that in the crab Chasmagnathus, spaced and massed training with an opaque screen moving overhead produced different forms of long-term habituation (LTH) of an escape response: LTH acquired by spaced but not by massed training was affected negatively by a change in context, provided by different visual cues around the bowl in which animals are kept. In the fruit fly D. melanogaster, the incidence of context on visual learning was analyzed using the flight simulator (see Section 1.26.3) in which a fly has to learn to fly stationary toward surrounding T-shaped patterns (upright and inverted) used as landmarks and presented on a surrounding screen. Context variation in this aversive learning paradigm was provided by a change in the color of the illuminating light (Liu et al., 1999). Normal flies transferred appropriate responses toward patterns from a trained to a new context providing that the chromatic differences between the two contextual lights were not too large (Liu et al., 1999). MB defective flies were unable to realize such a transfer and could not therefore remember the information learned in one context in a different one. These results suggest that the MBs help to stabilize visual memory with respect to context changes and thus allow the memory of an event to be stored and then retrieved in different situations (Liu et al., 1999).

Matsumoto and Mizunami (2004) have shown that crickets Gryllus bimaculatus associate one of a pair of odors with water reward (appetitive US) and another odor with saline solution (aversive US) under illumination, and learn the reversed contingency in the dark. Thus, crickets solved this variant of the transwitching problem (see above) and the visual context affected learning performance only 
when crickets were requested to use it to disambiguate the meaning of stimuli and to predict the nature of reinforcement.

Bumblebees have also been trained in a transwitching problem to choose a $45^{\circ}$ grating and to avoid a $135^{\circ}$ grating to reach a feeder, and to do the opposite to reach their nest (Fauria et al., 2002). They can also learn that an annular or a radial disk must be chosen, depending on the disk's association with a $45^{\circ}$ or a $135^{\circ}$ grating either at the feeder or the nest entrance: in one context, the nest, access to it was allowed by the combinations $45^{\circ}+$ radial disk and $135^{\circ}+$ annular disk, but not by the combinations $45^{\circ}+$ annular disk and $135^{\circ}+$ radial disk; at the feeder, the opposite was true (Fauria et al., 2000). In both cases, the potentially competing visuomotor associations were insulated from each other because they were set in different contexts. Comparable behavior was found in honeybees where distinct odors or times of the day (Menzel et al., 1998) were the occasion setters for a given flight vector.

Further examples for contextual learning in honeybees could be provided (e.g., Gerber and Menzel, 2000). The rich Russian literature on this subject is summarized in Kartsev (1996) and MazokhinPorschnyakov and Kartsev (1994), but they would be redundant for the main conclusion of this section which is that there is abundant evidence of conditional learning in invertebrates, which can be described as occasion setting or contextual learning. However, the nature of the associations underlying this kind of learning and its neural substrates remain unclear.

\subsubsection{Memory Systems}

Memories exist in multiple forms and functions. They are categorized according to their physiological substrates along a timescale as short-term, mid-term, and long-term memory (STM, MTM, LTM), referring to ongoing neural activity as the storage device of STM, intercellular signaling cascades leading to MTM, and gene activation, protein synthesis, and new structures underlying LTM. The transitions between these memory stages or phases can be sequential or parallel, processes referred to as physiological correlates of consolidation, a phenomenon originally known from human psychological studies (see Human Cognitive Specializations) capturing the fact that over time early, vulnerable forms of memory are converted into more stable and long-lasting forms (Ebbinghaus, 1964; Müller and Pilzecker, 1900).

Two processes of memory formation have already been introduced: the distinction between phylogenetic (the species' memory) and individually acquired memory (memory from learning). The relationship between these two forms of memory concerning their different molecular and cellular substrates - but also their corresponding mechanisms of expression (Fox et al., 1998) - is of utmost importance in the study of behavior and cognition, but is poorly understood. Here we focus on experience-dependent memory.

The term experience-dependent memory subsumes two processes in the brain, storing and retrieving information. A content of memory that is potentially retrievable but not actually retrieved is often referred to as 'remote memory', whereas 'working memory' captures the fact that retrieved and updated information exists in an active form that allows predictions to be made about potential outcomes of actions. Working memory is probably the most important concept in describing cognitive processes, since it is considered the interface between evaluated earlier events and future events in the context of the animal's current needs and motivations. Memory systems are also categorized according to their contents, and in vertebrates particular brain structures are related to it, for example procedural memory (e.g., cerebellum), episodic memory (hippocampus, prefrontal cortex), and emotional memory (amygdala). Whereas procedural memory certainly exists in invertebrates and may be distributed over their ganglionic nervous systems, it is debatable whether any animal possesses episodic memory, the ability to carry out long-term recall of sequences of events or narratives (see, for instance, Suddendorf and Busby, 2003, and reply by Clayton et al., 2003a). In humans, this property is intimately related to the functions of the hippocampus and cerebral cortex. It is argued that food-storing birds may develop an episodic-like memory about a kind of food stored at a certain place and at a certain time. Pollinating insects certainly control their foraging activities according to the kind of food they collect at a particular place and at a specific time of day, but it is unknown whether they make decisions between options integrating the what, where, and when of potential food sites (see Section 1.26.7).

Memory systems are highly dynamic and content sensitive. Any retrieval from the memory store will change its content due to the updating process in working memory. It is this updating process that may lead to extracting rules which underlie generalization, categorization, and implicit forms of abstraction (see Section 1.26.7). Furthermore, retrieval from memory store also induces new learning, and consequently consolidation into new 
memory, a process referred to as 'reconsolidation' (see discussion below).

It may be expected that the structure and dynamics of memory systems have been shaped by the evolutionary history of the species, and may thus reflect species-specific adaptations to the requirements posed by the environment. Little is known about these ecological adaptations of the memory system, because animal models of memory are rarely studied with respect to their natural behavior in order to detect possible correlates between behavioral and memory dynamics. However, appetitive learning in the honeybee provides certain insights into this question (see discussion below).

\subsubsection{Physiological Correlates of Memory Systems}

In bacteria and ciliates the memory for sensory adaptation and habituation of innate responses lies in the temporal dynamics of second messengers and their targets (see Section 1.26.2). The nematode C. elegans habituates to mechanical stimulation, and the duration of the memory depends on the number and intervals of the stimuli. Since retention of habituation differs for different chemical context conditions, it has been proposed that some form of associative learning may be involved (Steidl and Rankin, 2002). The $24 \mathrm{~h}$ memory, but not an early memory, depends on protein synthesis, thus indicating an early and a late memory phases. C. elegans provides excellent opportunities to study the molecular, cellular, and network properties of learning and memory, but since associative learning and its memory phases have not yet been convincingly documented, this model system awaits further progress before it will become useful for such studies (see Rankin, 2004 for further discussion).

The memories of various forms of learning have been intensively studied in several species of mollusks (Tritonia diomedea, Hermissenda crassicornis, Limax maximus, L. stagnalis, Helix pomatia, Pleurobranchaea californica, A. californica; Byrne, 2002). The focus in these studies lies on nonassociative forms of learning such as habituation and sensitization and on their physiological correlates, depression and facilitation. Pavlovian conditioning was studied in Hermissenda, Limax, and Lymnaea, and as in nonassociative learning, two major phases of memory were found, STM and LTM. The cellular correlates of short-term and long-term sensitization have been studied in greatest detail in Aplysia (Kandel, 2001). Short-term sensitization lasts for seconds and minutes and involves the modification of neuronal membrane properties and synaptic efficacy, often through the alteration of the phosphorylation state of existing proteins. Long-term sensitization lasts from days to weeks, depending on the training protocol (spaced trials lead to longer memory than massed trials). It requires synthesis of new macromolecules, since the inhibition of either gene transcription into mRNA or translation of mRNA into protein blocks long-term sensitization. In its most persistent form, long-term sensitization involves morphological changes and neuronal growth. In all these respects, the studies of Aplysia sensitization are exemplary and paradigmatic for any research on the cellular basis of learning and memory (Milner et al., 1998). In the context of the relationship between phylogenetic and experiencedependent memory, studies on the mechanistic relationship between development and learning are particularly interesting (Carew, 2002). In Aplysia, the nonassociative forms of plasticity in the sensory-motor connection of the siphon withdrawal response appear sequentially during early development: first habituation, then dishabituation, and then sensitization, indicating that the two facilitatory processes dishabituation and sensitization are mechanistically different. This interpretation is supported by the finding that the sequential appearance of plasticity phenomena at the sensory motor synapses corresponds to these forms of plasticity. Synaptic decrement of the sensory-motor synapse appears first in development, then facilitation of the decremented EPSPs, then facilitation of the nondecremented EPSPs, and, finally, an inhibition of nondecremented EPSPs appears in stage 12 of Aplysia development. The development of the inhibitory process can be nicely related to a maturation effect of sensitization in which strong stimuli become less effective in later developmental stages. Follow-up studies (Nolen and Carew, 1988) also demonstrated in adult Aplysia that dishabituation and sensitization are two different forms of facilitatory plasticity, at both the behavioral and the neural levels. Furthermore, it was found that long-term forms of sensitization emerge at the same time of development as short-term forms (stage 12), indicating that STM and LTM memory are mechanistically interrelated (Wright et al., 1996). These studies are of general importance because they document that the nonassociative forms of learning (habituation, sensitization) reflect not only two opposing processes but rather are composed of four behavioral processes, two decrementing (habituation, inhibition) and two facilitatory.

Using molecular genetic tools in Drosophila, four distinct memory stages have been found following 
aversive olfactory conditioning: STM, MTM, anesthesia-resistant memory (ARM), and LTM (Tully et al., 1994). Among the several mutants that have been analyzed with respect to their memories, rutabaga (rut) and amnesiac (amn) yielded the most information about their cellular mechanisms and the localization of STM and LTM in the Drosophila brain (Heisenberg, 2003; Isabel et al., 2004). Rut encodes a calcium-sensitive adenylylcyclase, and amnesiac encodes a neuropeptide similar to vertebrate PACAP (pituitary adenylylcyclaseactivating peptide). Rut mutants learn normally, but suffer from reduced STM that can be rescued in transgenic flies expressing the gene in a subpopulation of mushroom body neurons ( $\gamma$-lobe neurons; Zars et al., 2000). Amn mutants lack PACAPexpressing neurons, and two of these neurons extrinsic to the mushroom body are essential for the transition to LTM (Feany and Quinn, 1995). Structural mutants with lesions restricted to the alpha lobe of the mushroom body specifically abolish LTM (Pascual and Preat, 2001; Dubnau et al., 2001). Taken together with the analysis of several other single-gene mutants, these observations suggest that olfactory learning and memory depend, at least in part, on the activity of $\mathrm{MB}$ neurons. Different $\mathrm{MB}$ neurons may be involved in storing different memories, but currently nothing is known about how the transfer occurs between these neurons during consolidation from STM to LTM. So far only very few of the many neurons certainly involved in memory formation in Drosophila have been studied. It is estimated that more than 1000 genes are transcriptionally regulated during olfactory LTM formation (Dudai, 2002).

Reward learning in honeybees initiates a sequence of memory phases which lead to long-lasting memory passing through at least four forms of memory (Menzel and Müller, 1996; Menzel, 1999). An associative-learning trial induces an early form of shortterm memory (eSTM) in the seconds range. This memory is highly dominated by appetitive arousal and sensitization, is rather unspecific, and is quickly converted into a late STM (ISTM). At the cellular level, stimulus association is reflected in the convergence of excitation of the conditioned stimulus pathway of the (odor) via nicotinic acetylcholine receptors (nAChRs) in the antennal lobe and the $\mathrm{MB}$, and the pathway for the unconditioned stimulus, the putatively octopaminergic neuron $\mathrm{VUM}_{\mathrm{mx} 1}$, most likely acting on octopamine receptor II receptors. In the antennal lobe, both cAMP/PKA and $\mathrm{Ca}^{2+}$-dependent PKC are upregulated during STM, and the cAMP/PKA signaling cascade is indicative of the associative component (Müller, 2000).
However, unlike in Drosophila, blocking the cAMP/PKA pathway does not interfere with learning and STM. The transition to MTM is a rather slow process and makes the memory trace unsusceptible to retrograde amnesic treatments. Single and multiple learning trials lead to different long-term forms of memory (LTM, see discussion below). An important molecular component in the transition to LTM formation is enhanced and prolonged PKA activity after multiple learning trials. Two lines of evidence support the conclusion that LTM formation requires enhanced PKA activity shortly after multiple trial learning, but is not involved in the learning process itself: (1) blocking NO synthase during ISTM reduces PKA activity and impedes LTM formation (Müller, 1996); (2) enhancing PKA activity by uncaging cAMP in the antennal lobe after a single learning trial facilitates the formation of LTM in the same way as multiple trials do (Müller, 2000). MTM is characterized by a first wave of PKC activity (Grünbaum and Müller, 1998). The constitutive activation of PKC is a proteolytic process of formation of PKM that lasts for several hours. Inhibition of proteases in the whole brain reduces the formation of PKM and blocks retention during the MTM phase. LTM formation is also blocked in this way, indicating that protein synthesis-dependent LTM and high levels of longlasting PKC activity (until the third day after conditioning) are formed parallel to PKM-dependent MTM.

Two forms of LTM must be distinguished in honeybees: early LTM (1-2 days) characterized by translation-dependent retention and constitutively active PKC, and late LTM ( $\geq 3$ days) characterized by transcription-dependent retention and no more enhanced PKC activity. The two forms of LTM arise differently, after massed and spaced multiple learning trials (Menzel et al., 2001). Memory resulting from spaced trials is blocked by protein synthesis inhibitors, whereas memory resulting from massed conditioning trials (intertrial interval $30 \mathrm{~s}$ ) is independent of protein synthesis.

\subsubsection{Working Memory: Capacity and Duration}

The capacity and time span of working memory has been estimated in invertebrates only for the honeybee in the appetitive context of nectar foraging. As pointed out above, very short intervals $(<1 \mathrm{~min})$ between a learning and a test trial lead to high but rather unspecific responses, while long intervals lead to specific responses of the learned stimulus. Chittka et al. (1997) recorded the frequency of intervals between stay and shift flights made by bumblebees 
foraging on more than two plant species. Stay flights appear at shorter intervals $(\sim 2 s)$ than shift flights, indicating that immediate choices are dominated by the most recent and the most effective STM, but reference to more remote memories needs more time. To interpret it from another perspective, one could say that longer intervals release working memory from the dominant memory of the last visit and allow for contributions from an earlier memory that has meanwhile been consolidated. Greggers and Menzel (1993) found for bees foraging in a patch of four feeders that delivered different flow rates of sucrose solution that they store the reward properties of these feeders in working memory. Similar results were found for eight feeders, indicating that the reward properties of eight feeders can also be stored in feeder-specific memories. The capacity of working memory is, therefore, at least eight items. The time range of these specific working memories could be estimated as lying around $6 \mathrm{~min}$.

Recently, working memory in foraging honeybees has also been estimated using the DMTS procedure (see Section 1.26.4 and Giurfa et al., 2001), in which a free-flying bee is exposed to a visual stimulus (the sample) through which it should fly to then subsequently choose between two options, one of which corresponds to the sample. If the bee matches its choice to the sample it is rewarded with sucrose solution (Giurfa et al., 2001). Using this paradigm, Zhang et al. (2005) estimated the duration of the working memory for the sample, which allows a bee to choose between alternatives after passing though it. The duration of such a working memory was around $5 \mathrm{~s}$. Longer delays between exposure to the sample and subsequent choice of stimuli result in random choices.

\subsubsection{Reconsolidation}

When memory is retrieved from a remote store by exposing the animal to the learned stimulus without reinforcement (extinction), two processes are initiated: extinction learning, due to the fact that the stimulus originally associated with reinforcement is now presented without it, and reminder learning, which may either recruit the original stable memory about the learned stimulus and bring it back into an unstable form (trace dominance hypothesis, see discussion below), or it initiates a new learning trial based on the fact that a learned stimulus also activates the reward system and thus initiates new learning (internal reinforcement hypothesis, see below). Both extinction and reminder learning are followed by their respective consolidation processes: consolidation of an extinction memory and reconsolidation of the reminder memory. Studies in the crab Chasmaganathus (Pedreira and Maldonado, 2003) and the honeybee (Stollhoff et al., 2005) showed that the strength of these two consolidation processes depends on both the strength of the reminder memory and the strength or number of extinction trials. These observations resemble findings in vertebrates showing that the presentation of an extinction trial does not always result in extinction alone, rather it may lead to an opposing behavioral phenomenon, the stabilization of the response learned earlier. In this case, the extinction trial transfers the old memory from an inactive, stable protein synthesis-independent memory into an active and unstable protein synthesis-dependent reminder memory (Nader, 2003; Dudai and Eisenberg, 2004). In the honeybee, the balance between the extinction and reminder learning processes and their respective consolidation processes depends on the number of extinction trials. Extinction learning is dominant after two extinction trials, whereas reminder learning is expressed in a recovery from extinction and is induced by many (five) extinction trials. Consolidation of reminder learning (reconsolidation) depends on protein synthesis, which indicates that a new learning process is going on, as shown in the vertebrate studies. Nader (2003) and Dudai (2004) proposed the hypothesis of "trace dominance" and interpret the results as a competition between consolidation of extinction memory and reconsolidation of reminder memory "with the dominant one being the one most affected by protein synthesis inhibition." This hypothesis can explain the observations on aversive learning in the crab Chasmaganathus (Pedreira and Maldonado, 2003) but not those on appetitive learning in the honeybee (Stollhoff et al., 2005). In Chasmaganathus extinction memory and its consolidation are dominant after either one strong or many extinction trials, whereas a weak or only one extinction trial leads to dominance of reminder learning and of its corresponding reconsolidation. Exactly the opposite was found in bees. One reason might be a difference between consolidation processes induced by aversive or appetitive learning. Furthermore, the trace dominance hypothesis proposes that either the reconsolidation of the reminder memory or the consolidation of the extinction memory occurs according to an 'all-or-none' rule. The bee data do not support such a conclusion, because inhibiting consolidation of extinction memory results in an opposite behavioral effect than the inhibition of reconsolidation of reminder memory. It was hypothesized that in bees these consolidation 
processes take place in parallel, rather than following an 'all-or-none' rule (Stollhoff et al., 2005).

The results on reconsolidation in the honeybee can be explained via properties of the reward system in the bee brain. Hammer (1993) found that the reward neuron $\mathrm{VUM}_{\mathrm{mx} 1}$ not only codes for appetitive reinforcement of odors, but also learns to respond to the conditioned odor stimulus, and an extinction trial does indeed activate the VUM neuron (Hammer, 1997). This means that an extinction trial will lead to new appetitive learning without an external reinforcing stimulus. This is exactly what was found: two forms of learning, one based on the lack of external reinforcement (extinction learning), and one based on the internal existence of reinforcement (reminder learning). These conditions are best captured by the 'internal reinforcement hypothesis', which states that the balance between extinction and reminder learning depends on the relative strength of the internal reinforcement. The balance will be shifted to the internal reinforcement with more unrewarded presentations of the learned stimulus.

\subsubsection{Ecology of Memory Systems}

From an evolutionary point of view one may expect that memory dynamics are adapted to choice behavior under natural conditions. Foraging in pollinating insects is a behavior with a highly regular sequential structure of events ranging from actions within seconds to those separated by months and thus may offer the opportunity to relate memory structure and ecological demands (Menzel, 1999). Different memories are consulted during the sequence of events during foraging. In the bee, the time courses of successive behaviors during foraging match the temporal dynamics of memory stages. Choices between flowers within the same patch quickly succeed each other and are performed during eSTM. Choices between flowers of different patches occur after the transition to ISTM. Successive bouts are interrupted by the return to the hive such that flower choices in a subsequent bout require retrieving information from MTM. The separation between the two forms of LTM may be related to the periods when flower patches are in bloom (Menzel, 2001).

Although these ecological considerations are highly speculative, they indicate, on the one hand, that sequences of natural behavior need to be examined with respect to the intrinsic properties of the neural machinery underlying memory formation. On the other hand, they emphasize the necessity of considering the results of laboratory studies on memory formation in the context of natural behavior. Only comparative studies will help us discern which properties reflect general mechanisms and which indicate species-specific adaptations, and invertebrates offer a huge range of ecological adaptations. This conclusion supports the fact that more studies on the natural behavior of animal models of memory are necessary. To which extent do the different memory phases of Drosophila or Aplysia correlate with specific sequences of their behavior? To which extent are aversive and appetitive memories coincident with respect to their dynamics, given the fact that they respond to different natural sequences and behavioral timing? These questions require comparative studies of memory that allow for the natural context in which memory is to be employed, a requirement that is seldom met by studies on invertebrate memory.

\subsubsection{Representation and Planning, Observatory Learning; Navigation; Communication and Individual Recognition}

One of the most important steps in conceptualizing cognition is the distinction between implicit and explicit knowledge. Explicit knowledge may - in a strict sense - exist only in humans. Animals (other than primates) might possess only implicit knowledge, but this does not rule out the possibility that certain forms of knowledge might reach an 'explicitlike' status specific for the animal species in question in the sense that internal operations on memories (or representations) are performed without motor expression of such operations. A telling example of this form of knowledge is the choice behavior of food-storing birds which makes their choices dependent on what kind of food they have stored and when and where they have stored it (Clayton et al., 2003b). Thus, expectation, attention, planning, and decision making could be useful terms for animals, even if we assume that they possess only implicit knowledge. If such terms are used, we assume that the animal retrieves a memory whose structure allows two or more alternative outcomes to be evaluated before any motor action is performed. We shall address the question here whether it is reasonable to assume such forms of internal processing in invertebrates, in particular, in insects (e.g., the honeybee) and cephalopods (octopus) (for Drosophila see Greenspan and van Swinderen, 2004). Do these animals have a memory in the sense that its contents can be recollected outside of the immediate sensorymotor control, and used for internal operations? 
There are good reasons for rejecting this kind of questioning when it comes to understanding invertebrate behavior. Too often, mentalistic reasoning has led to obscure arguments and untestable hypotheses. On the other hand, searching for experimental conditions that would allow us to address the internal processing of the brain devoid of sensory-motor control, its spontaneity and creativity, in even such a tiny brain as that of insects, may help to do better justice to the complexity of neural functions in bigger brains. In most behavioral studies, inference about internal processing can be made only indirectly by observing changes in behavior. In the honeybee, one can study a communicative process between foraging animals transcending the usual limitations of behavioral studies in invertebrates, and 'read' their reports on what they perceived, what they learned, and what they consider to be worth reporting. This unique situation was ingeniously exploited by von Frisch (1967), who discovered through it a whole range of sensory capacities and experience-dependent faculties. More recently, work on honeybees has benefited from cognitive perspectives (Menzel and Giurfa, 2001; Giurfa, 2003), and it is on this aspect that we focus in this article.

The topics of observatory learning, navigation and communication are addressed here because it is under these conditions that learning transcends elementary forms of association in particularly clear ways. The evaluating signal for storing experience must come from internal nervous system conditions at the time of learning, depends considerably on the motivational level, requires attention to a subset of stimuli, and is adjusted to the animal's own behavior in an intricate way. The signals learned are usually composed of multimodal inputs which cannot be isolated from each other, and the motor performances involve sophisticated sequences of motor programs. As will be seen, it is still very difficult to prove the cognitive nature of the processes, because more elementary interpretations need to be carefully considered. Close sensory-motor connections, simple partial matching strategies between experienced and remembered constellations, sequences of picture memories, and other forms of elementary solutions to complex conditions must be discarded before elaborating on an animal's cognitive sophistication.

\subsubsection{Observatory Learning}

Observatory learning differs from associative learning in the lack of an obvious external reinforcing stimulus. Thus, an animal capable of observatory learning should be able to internally evaluate environmental conditions as well as its own actions by activating a circuit that informs it about the value of signals and actions to which the animal is simply exposed.

The cephalopod mollusk Octopus vulgaris is able to learn a visual discrimination by observing the behavior of conspecifics (Fiorito and Scotto, 1992; Fiorito and Chichery, 1995; Fiorito et al., 1998). In the experiment, one group of animals (demonstrators) was first trained to attack one of two simultaneously presented colored balls. When the animal attacked the correct ball, it was rewarded with food which was attached to the opposite side of the ball. If the animal chose the wrong ball, it was punished with an electric shock. In a second phase, untrained octopuses (observers) watched demonstrators attack that stimulus from an adjacent tank. No contingent reward or punishment was given to the demonstrator during this observation period. In the final phase, the observers were exposed to the two balls. In over $80 \%$ of all cases, they only attacked the ball of the same color as that attacked by the demonstrator. Untrained animals do not exhibit such a strong preference. This vicariously acquired discriminatory behavior is stable for at least 5 days after the observational phase.

The salticid jumping spider of the genus Portia was exposed to a three-dimensional maze which the animal could oversee in its entirety (Tarsitano and Jackson, 1997). One of the two wire paths led to a food lure, the other did not. After visually scanning the entire track, at the first trial the animal already made $75 \%$ correct choices at that vantage point. This remarkable display of problem solving requires planning and expectation, performed by a brain of only several hundred micrometers in diameter. Honeybees in a swarm searching for a new nest site inspect potential locations by running in various directions along the walls of the cavity and performing recruitment dances at the surface of the swarm according to the suitability of the cavity as a nest site (its size, humidity, proximity, and possibly other parameters (Seeley, 1977)). The kind of individual learning during these behaviors can only be addressed as observatory learning, because no reward is provided to the animal inspecting a cavity. The search is focused exclusively on potential nest sites: the animal has to integrate a large range of sensory inputs which are accessible only by its own exploratory behavior, and must evaluate them according to an innate template, which cannot be totally fixed, because otherwise a bee would never find a suitable new nest site. Many more such forms 
of observatory learning exist in insects, crustaceans, and cephalopods, but only few have been studied carefully, because natural conditions are required for the animal to initiate its exploratory behavior, and it is often difficult to evaluate the learning during observation.

\subsubsection{Navigation}

Navigation is an orientation strategy that allows animals to travel between defined locations without having direct sensory access to these locations. In this sense navigation differs from general orientation and guidance, which include all forms of spatial relationships between the animals' body positions and trajectories of movement relative to sensory conditions. Navigation allows animals to travel over rather long distances relative to their body size and sensory range, according to their knowledge of the structure of their surroundings, which they acquire by sequential experience. Several classifications of navigation have been proposed, reflecting different conceptual frameworks, for example, route and local navigation (O'Keefe and Nadel, 1978), cognitive mapping, piloting and dead reckoning (Gallistel, 1990), egocentric and allocentric navigation (Wehner, 1992; Thinus-Blanc, 1987), random navigation, taxon navigation, praxis navigation, route navigation and local navigation, graph and map navigation (Gillner and Mallot, 1998). Irrespective of whether the classification focuses on sensory, neural, or mental processes, or whether the structure of the external signals was referred to, two basic navigation strategies emerge from these various viewpoints: route strategy (also called graph structure of navigation; Gillner and Mallot, 1998) and local navigation or map strategy (also called cognitive mapping; Tolman, 1948; Gallistel, 1990; Pastergue-Ruiz et al., 1995). Besides these strict definitions, the term navigation is often used in loose terms, for example, when C. elegans explores its environment, and genes are characterized that control elements of this exploratory behavior in different ways (Gray et al., 2005; Rodger et al., 2004), or when Drosophila runs between two or more visual marks in a rather stereotypic way (Götz, 1975). It is an interesting but yet unresolved question whether genes identified by testing these very simple forms of movement may also be involved in controlling the ontogenetic setup and switching the circuits that underlie navigation in the strict sense. A hint in this direction comes from the observation that the foraging gene (Engel et al., 2000) involved in exploratory behavior in Drosophila larvae appears to be more strongly expressed when honeybees switch to foraging behavior (Ben Shahar et al., 2002).

Place learning in a small environment like the Morris water tank provides a useful paradigm for studying components of navigation in small mammals like rats, and their neuronal underpinnings (Morris, 1982). A similar attempt has been followed for the cockroach by providing a cool place on a hot platform (Mizunami et al., 1998). In such a paradigm, called 'the Tennessee Williams paradigm' for obvious literary reasons, a cockroach learns to choose the cooler place using the spatial relationships between landmarks in the environment, though in a less robust way than rodents. In addition, it was found that bilateral lesions in the MB region reduce place learning. Coincidently, crickets may learn to use responses to olfactory stimuli at two different contexts (Matsumoto and Mizunami, 2004), or to combine visual and olfactory cues in choosing a particular exit hole among several identical holes in order to escape from a circular arena (Scotto-Lomassese et al., 2003). MB neurogenesis seems to be crucial for the last task, since irradiating the dividing neuroblasts around this structure suppresses this ability.

In studies with rodents, an essential aspect relates to the distinction between navigation according to landmarks (true 'spatial-based' navigation), a hippocampus-dependent form of behavior, and 'cuebased' navigation, a behavior which in mammals is independent of the hippocampus (Morris, 1982). It is not yet known whether structures of the arthropod brain are differentially involved in these two paradigmatically different forms of navigation, and in particular whether the $\mathrm{MB}$ in the insect brain may be a structure necessary for relational, landmarkbased navigation. However, a comparison between studies of the cockroach (Mizunami et al., 1998), and the cricket (Scotto-Lomassese et al., 2003) may provide an insight into these questions, because the cockroach study would reflect a case of spatialbased navigation, since the safe place in the arena had to be found on the basis of spatial relationships between external landmarks. The cricket study, on the other hand, could be considered as a case of cuebased navigation, because the correct and the wrong exit holes were marked by nonambiguous cues. Interestingly, the same structure, the MBs, was crucial for both kind of performances, although in the case of crickets it was the formation of new MB-constitutive neurons that was affected, and not the MB circuit itself, as in the cockroach study (Mizunami et al., 1998).

Below we focus on navigation in social Hymenoptera, because the relationship between 
route strategy and map strategy has been the subject of intensive and controversial debates in these insects. Traditional thinking about navigation in insects was based on the notion that a toolbox of rather simple sensory-motor routines is at the animal's disposal and their stepwise application may lead to the solution of isolated, rather independent navigational tasks. These robot-like concepts were developed by experiments based on the analysis of route learning, sometimes even at such a small scale that target-related orientation - rather than navigation - was tested (Collett and Collett, 2002). Bees and ants traveling between their nest and a food source learn the vector components of their movements (direction and distance) by a dead reckoning (path integration) process (Wehner, 1992). Landmarks experienced en route may serve to calibrate measured distances (Srinivasan et al., 2000a), thus reducing the rotatory and translatory errors that may accumulate during path integration (Wehner et al., 1996; Graham and Collett, 2002). Furthermore landmarks may provide procedural information about turns to make and distances to travel next (Collett, 1996, 1998; Collett and Collett, 2000; Kohler and Wehner, 2005) such that apparently complex performances could be based on simple rules of learning sensory-motor connections. Honeybees can, for instance, learn to negotiate complex mazes of adjacent boxes by associating colored disks with right or left turns (Zhang et al., 2000; Srinivasan and Zhang, 2004). Since bees are able to refer to a compass direction even when the sun is not available (e.g., under an overcast sky and as measured by their dance performance; von Frisch, 1967; Dyer and Gould, 1981), landmarks also serve as compass-related directional cues that could be understood as a backup system, but it could also mean that landmarks are incorporated into a geostable map-like memory of the experienced environment (see discussion below). The redundancy of landmarks is thought to be reduced by reference to contextual information such as the visual panorama (Collett et al., 2002; Kohler and Wehner, 2005). Consequently, 'isolated' landmarks may not be sufficient for successful navigation, or their information might be suppressed under competition conditions, as often occurs in experiments where bees are transported to an unexpected release site. The animal may then shift its reference to salient signals like farther-ranging landmarks. Furthermore, a dissociation of behavior may occur that seems to indicate the combined action of separate navigational cues. For example, bees flying in a narrow tunnel search at the correct distance if both local and contextual cues are available. If one of the two cues is shifted or removed, then the contextual cue appears to be the more important one (Collett et al., 2002). Under more natural conditions, a dissociation of two forms of distance estimation, odometry by the visual flow field (Esch et al., 2001; Srinivasan et al., 2000b) and landmark sequences, can be found. Chittka and Geiger (1995) set up an experiment in which sequentially experienced landmarks guided free-flying bees over hundreds of meters to a feeding station. The bees searched both at the absolute distance as measured by odometry and at the location designated by the sequence of landmarks. The directional component of flight is also controlled by landmarks (Collett, 1996), and even novel directions can be traveled if a particular landmark constellation simultaneously triggers the retrieval of memories for two different flight directions (Menzel et al., 1998).

Training bees along a route will establish a particular spatial memory structure, and very different forms of spatial memory may result from exploratory orientation flights that bees perform before beginning their foraging life (von Frisch, 1967; Capaldi et al., 2000). Indeed, it was found that bees lacking route training were able to return to the nest from sites all around the hive, located several hundred meters away (Menzel et al., 2000), a range over which orientation flights are performed (Capaldi et al., 2000). Comparing such bees with those trained along a route showed that the working memory of the route dominated initial navigation, leading the animals in the wrong direction and first suppressing the memory that later quickly leads the animals back to their goal (the hive). Since only the initial flight path was monitored in these experiments, and vanishing bearings were taken as measures of navigation, inadequate concepts were derived because the multitude of spatial memories was not considered (Wehner and Menzel, 1990; Dyer, 1991; Wehner, 1992).

Most of the experiments on the role of landmarks on path integration, compass-driven sequential pictorial learning, and the relationship between 'isolated' landmarks and contextual landmarks were carried out in miniature environments which forced bees to fly through narrow entrances into small boxes or mazes (Collett and Collett, 2002). All these tests made forced route training necessary, avoided testing the sequential experience of natural landmarks in unhindered flight, and did not expose the bees to the temporal and spatial structures they would normally experience in free flight. Certainly, such experiments have the advantage of observing the bee over the full flight close to the goal, but the limitations for generalization to natural conditions 
are obvious, since they reflect only the approaching components and orientation strategies that bees may adopt when close to the goal. Navigation in the real bee flight range (several kilometers) must be guided by compass-related learning of multiple sequences of landmarks that are visible under different perspectives and over different ranges of the flight path, some of which are only visible when the bees get close to them. The essence of the navigational problem - whether an animal is able to orient itself and infer a direction of movement along a novel path aiming toward another location that is not directly accessible - cannot be addressed by such reduced experimental setups. Questions that are not asked in an experiment cannot be answered by it. Working under natural conditions, however, limits the possibility of untangling the relevant parameters underlying navigation strategies. Therefore, such 'naturalistic' experiments have a different quality. They are necessarily more descriptive and less analytical, but they provide clues for behavioral capacities while allowing a rather limited mechanistic interpretation. Recently, a method based on harmonic radar detection of freeflying bees was applied that allows researchers to observe a bee when it travels over natural distances (see below).

By far most of the experiments on insect navigation were carried out with ants (the wood ant Formica rufa, the desert ant Cataglyphis, the Australian desert ant Melophorus bagoti) and the honeybee. The data were often used to transfer the concepts developed for ants to bees (and even to arthropods in general; Wehner, 1992), implying that navigation strategies are similar in running and in flying insects. Bees fly over distances of a few kilometers, cruising well above ground, with a bird's-eye view; ants run a few tens of meters. It would be rather strange if the navigation systems of running and flying insects, in particular their 'cognitive' (integrative) levels, were similar. Experiments addressing distance estimation in ants and bees clearly show, for instance, that these two insects differ dramatically in their manners of estimating distance. While bees seem to use the optic flow field (the relative displacement of the visual field on the insect retina) experienced en route to the goal, ants do not seem to rely on optic flow to the same extent (Ronacher et al., 2000). Recently it was shown that ants can estimate the distance to travel within a tunnel in the dark without any kind of visual information (ThielinBescond and Beugnon, 2005), thus underlying the role of proprioceptive cues for distance estimation in ants.
1 26.7.2.1 The map concept and its experimental support Local navigation or map-based strategy allows goal-directed decisions at any place and toward any intended location in the experienced area, thus resulting in a transfer between routes and inference of novel routes. Such a strategy has until recently not been convincingly documented for insects, and is the subject of lively debate (Giurfa and Capaldi, 1999; Collett and Collett, 2002). Navigational memories that are more flexible than route memories are found in experiments that avoided route training in bees and proved that bees are able to return to the hive from any place around the hive within a rather short time (Menzel et al., 2000). It was concluded that bees learn features of the landscape during their orientation flights (Capaldi et al., 2000) and establish a special 'landscape memory' that relates landmarks to the bees' central place, the hive. It was only recently that the structure of this 'landscape memory' could be critically tested using harmonic radar technology to track individual bees (Menzel et al., 2005). In this study, three test groups were studied and their flight paths recorded after they were released at many different release sites around the hive. The three test groups were: bees that were trained to a feeder placed at variable locations in close vicinity to the hive that was moved around the hive at a constant distance (VF bees) and that therefore did not develop a route memory; bees that were trained to a stationary feeder $200 \mathrm{~m}$ to the east of the hive (SF bees) and thus developed a route memory; and bees that were recruited by foragers that collected food at the stationary feeder ( $\mathrm{R}$ bees). It was found that all bees returned to the hive along fast and straight flights from all regions around the hive. SF and $\mathrm{R}$ bees did so after they had performed the vector (distance and direction) components of their trained or instructed route flights; VF bees returned after searching for a while. Most importantly, SF bees performed either direct flights back to the hive or via the feeder to the hive.

Several operations must be at the animal's disposal: (1) recalling memories of these vectors (segments with defined headings and distances) pointing toward the hive with a large number of landmarks all around the hive that are recognized from different viewpoints, (2) a shift in motivation (fly toward the hive or toward the feeder), (3) reference to the outbound vector components of the route flight from hive to feeder, and (4) addition and subtraction of the flight vectors for at least two sets of vector memories; those which would lead directly back to the hive, and those that lead from the hive to the feeder. It is difficult to imagine that these 
operations can be done without reference to vectors that relate locations to each other, and thus make up a map. The question now in bee navigation is not so much whether there is a map-like spatial memory, but rather 'What structure does this map-like memory have and how is it used?'. In any case, the maplike memory in bees is rich and can be used in a flexible way. Any model of bee navigation thus has to incorporate a strategy based on a map-like representation of the bees' large-scale home range and a freedom to choose between at least two goals. This further suggests that spatial relations between environmental features appear to be coherently represented in a map-like memory in insects as they are in other animals and humans (Gallistel, 1990; Shelton and McNamara, 1997; Klatzky, 1998).

Parsimony is a strong argument in the interpretation of experimental data, and has been applied rather strictly in studies of insect navigation (Wehner, 1992). However, it should not be overlooked that radical forms of parsimony as applied to behavioral science were (and may still, at least partially be), a historical burden. New approaches were required to correct for eliminating the brain in behaviorism and making too simple assumptions about the brain's functions in ethology. These cognitive approaches (cognitive ethology, psychology, neuroscience) provide us with novel avenues to brain function (Kandel and Squire, 1992). A frequently used argument in navigation studies, which states that reference to cognitive processing (a cognitive or mental map) must be avoided as long as 'simpler' explanations are at hand (Bennett, 1996), may warn us about potential traps, but should not be accepted as a ban. Furthermore, it is argued (Collett and Collett, 2002) that small brains, like that of the bee, need to solve their tasks with less 'cognition', meaning with a toolbox of loosely interrelated elementary functions rather than an integrated, allocentric level of spatial representation (see discussion above). It should be recognized that we simply do not know whether the integration of the multiple and complex sensory and procedural neural processes into a common spatial memory with geometric organization (a map) may not be a more economical and thus simpler way of representing sequential experiences during navigation (Griffin, 1984).

\subsubsection{Communication}

All sensory channels (besides magnetic sense) are used in invertebrates for communication, and elaborate sender-receiver systems have evolved for intersex communication, predator-prey relationships, and social interactions. Communication by pheromones has been addressed above (see Section 1.26.2). Optical signals include light emission by luminance organs in night-dwelling invertebrates ranging from unicellular organisms to crustaceans and insects (Lall, 1993; Buck and Case, 2002). Sex-specific coloration and movement patterns of body appendages or of the whole animal are often used to attract the other sex, and specific photoreceptors or visual interneurons have evolved (e.g., the flight maneuvers and the 'love spot' in diptera; Hornstein et al., 2000; Egelhaaf and Kern, 2002). Airborne sound and substrate vibration are most important signals for all three behavioral conditions of communication (intersex, predator-prey, social interactions; Cocroft and Rodriguez, 2005). Although the sensory, ecological, and evolutionary aspects of these communication systems have been often studied in great detail in invertebrates (e.g., sound communication in insects: Henry (1994), Gerhardt and Huber (2002); substrate vibration in spiders: Barth (2002), and in insects: Hölldobler and Roces (2000), Cocroft (2003); visual signaling in butterflies: Eisner and Aneshansley (1973); chemical signaling: (Hölldobler and Wilson (1990), Eisner and Meinwald (1995); see also Section 1.26.2), very little is known about the cognitive dimensions of these communication systems, for example, how the innate mechanisms interact with experience-dependent developmental processes, how the innate mechanisms are related to internal and external context conditions, whether learning shapes the communication process, and if communication leads to individual recognition (see discussion below). More is known in these respects about the ritualized movements ('waggle dance') used by honeybees to communicate distance and direction from the hive or the swarm to important places (potential nest sites, feeding, water or resin places). We therefore consider this form of communication in more detail.

1.26.7.3.1 The cognitive dimensions of dance communication in honeybees In the waggle dance, a dancing bee (Apis mellifera) executes fast and short forward movements straight ahead on the comb surface, returns in a semicircle in the opposite direction, and starts the cycle again in regular alternation (each waggle dance involves several of these cycles; von Frisch, 1967). The straight portion of this course, called a waggle-run, consists of a single stride (Tautz et al., 1996) emphasized by lateral waggling motions of the abdomen. The length of the single waggle-runs increases with the distance flown to reach the source, and their angles relative to gravity correlate with the direction of the 
foraging flights relative to the sun's azimuth in the field and sun-linked patterns of polarized skylight. Thus, by encoding the visually measured distance (Esch and Burns, 1995; Srinivasan et al., 2000a; Tautz et al., 2004) and the direction toward the goal, the waggle dance allows colony members to share information about the distance and direction toward a desirable goal (von Frisch, 1967; Seeley, 1995; Dyer, 2002). Although Karl von Frisch used the term "dance language," Premack and Premack (1983) correctly stated that the honeybee dances should not be called a language, based on the argument that there is no evidence that the bees can judge whether their dances conform to anything in their surroundings. This question can be addressed by asking whether a bee receiving information from the dance responds differently to the information depending on its own experience. Such experiments have yet to be performed. There is also no evidence yet that honeybees employ chain communication whereby an animal picks up on the received information without experiencing itself the primary signals inducing the dance. In his studies of dance communication within a swarm, Lindauer (1955) did not observe a bee changing its dance pattern until it had actually visited the second cavity, and these observations were verified more recently by Visscher and Camazine (1999), who observed no higher attraction of bees to dances which indicated the same location as the one for which they had previously been dancing. The authors also found that it takes a swarm longer to get started with the flight to a new nest site if the decision must be made between alternative nest sites, and they present arguments for some form of collective "quorum sensing" (Seeley and Visscher, 2004; see also below). Furthermore, the term "language" is also misleading, because there is (as far as we know) no semantics or grammar in the ritualized movements of the dance. "Indexical" or "iconic" (Bermudez, 2003) would be better descriptive terms to characterize the informational status of the dance.

Since navigating bees benefit from path integration (Wehner and Menzel, 1990; Dyer, 1998; Collett and Collett, 2002; Wehner, 2003), vector memories derived from recent flight paths might be recalled in the dance context. Indeed, path integration (which requires working memory in order to continuously record the angular and linear components of the animal's movements) provides ants and most likely also bees with 'global' vectors at the ends of their outbound paths, which allow them to follow straight trajectories of the appropriate distance and direction during their inbound path. Although the global vector is emptied each time the animal returns to the nest, desert ants can store a shortlived $180^{\circ}$-reversed form of a recently experienced homing path, and use it to guide their outbound paths toward previously visited locations (Wehner, 1992). Moreover, when trained bees arriving at a foraging target are held captive for several hours, they subsequently fly farther outward away from the hive along the same hive-target direction (Dyer et al., 2002). We may therefore assume that forager bees also store a form of global vector that they later recall in the context of the waggle dance. But does the waggle dance encode a global vector, an integrated form of the measures of distance and direction, and/or even code for a location?

Early detour experiments by von Frisch and colleagues (reviewed in von Frisch, 1967) indicated that the bees' visually driven odometer is primarily decoupled from the processing of directional information, indicating that no global flight vector is reported in the context of the waggle dance. When bees are compelled to fly a two-legged detour path to reach the goal, their dances indicate the direction of the straight line toward the goal (computed from the two legs of the detour), even when they followed the detour on the way back to the colony; but they signal the distances actually flown, and not the distance of the straight segment connecting the target and the hive's entrance. These early findings were recently confirmed by manipulating the navigational information provided to a dancing bee (De Marco and Menzel, 2005). Thus, one might ask whether the waggle dance encodes spatial information provided only by the actual flight path. The role of landmarks so far has been considered only in the context of resetting (Srinivasan et al., 2000b) or calibrating the odometer (Tautz et al., 2004) but not in the communicative process. The detour experiments by von Frisch suggest that the directional component reported in the waggle dance may also be derived from stored path integration coordinates of visually defined locations (landmarks). This idea is not without precursors. Early experiments showed that with increasing experience of the terrain, directional information available during the inbound flight may be computed for the purpose of directional indication in the waggle dance (Otto, 1959). If the waggle dance computes directional information which depends not only on the current state of the animal's path integrator, but also on information that the animal has associated with landmark views, that is, local vectors associated with landmarks (Etienne et al., 2004), navigating bees would rely not only on an egocentric, but also on a geocentric system of reference. 
It has been argued in the section on navigation (see Section 1.26.7.3) that the navigational strategies applied by foraging bees cannot be fully appreciated if one assumes a hive-centered egocentric form of spatial memory. Instead, it seems that the orientation flights of young or reorienting bees lead to a map-like spatial memory that appears to be derived from repetitive exposure to the same landmarks from different viewpoints. Given this capacity and the fact that bees are recruited by a dancing bee only after they performed their orientation flights, it is tempting to assume that bees attending a dance might recall from its memory of landmarks and homing vectors a corresponding outbound vector that is related to expected landmarks. Under these conditions neither the dance behavior nor the flight path of a recruited bee would be guided solely by two independent measures (direction and distance) but rather by an 'expectation' to arrive at a particular location. A component of this 'expectation' would be the route to be followed, as embedded in the map-like memory including sequences of landmarks. Indeed, already von Frisch (1968) stated that the effectiveness of waggle dances (in terms of successful recruitment) depends upon the foraging experience of the dance followers. When two groups of fellow bees have visited two different (and currently exhausted) unscented feeding places, contact with a dancer indicating the accustomed goal is much more effective than contact with a dancer indicating the unfamiliar one. In spite of these early findings, however, the role of stored navigational information on the decoding process involved in the waggle dance remains entirely unknown.

\subsubsection{Individual Recognition}

Cricket males perform rivalry songs, defend their territories, and fight against each other (Alexander, 1961; Adamo and Hoy, 1995); however, no clear evidence exists yet that winners and losers learn to recognize each other on an individual basis (Paul Stevenson, personal communication). The yellowblack patterns of the faces and the abdomen of the paper wasp Polistes fuscatus vary considerably, making it possible that individual animals in these small colonies might recognize each other (Tibbetts, 2002). More variable patterns with larger black components were found to be carried by individuals ranking higher in the nest hierarchy. Altering these facial and/or abdominal color patterns induces aggression against such animals, irrespective of whether their patterns were made to signal higher or lower ranking, and arguments - though not fully conclusive - have been provided stating that this altered aggressiveness may indicate individual recognition (Tibbetts and Dale, 2004). Although this study appears to indicate the first case of individual recognition in insects, it is rather likely (but not yet proven) that other invertebrates, in particular territorial cephalopods like octopus, should recognize each other on an individual basis.

An additional but in no way necessary component of individual recognition is 'self-recognition', the discrimination between signals from the animal's own body from those from the outside world. Do invertebrates experience 'pain', a form of self-recognition that includes an emotional and a warning component that points to the future? Locusts and crabs cast off body appendages when attacked. Do they experience different forms of sensory input when they perform these actions themselves or when the same appendages are removed? When honeybees lose their stinger the abdomen is damaged so much that the animal will die. It has been observed that alarm pheromone, which usually triggers an attack flight, induces stress analgesia via an opioid system in the honeybee (Nunez et al., 1997), potentially indicating that a preparatory response of the nervous system leads to a reduction of the strong sensory input from the body distraction. Opioids, which are usually associated with stress-induced analgesia, have been found in other invertebrates such as crickets (Jaffe and Blanco, 1994) and the praying mantis (Zabala et al., 1984), thus suggesting that their presence may serve to counteract the effect of nociceptive stimuli as in vertebrates.

E. O. Wilson states on the final page of The Insect Societies:

The insect societies are, for the most part, impersonal. The small, relatively primitive colonies of bumblebees and Polistes wasps are based on dominance hierarchies, and individuals appear to recognize one another to a limited extent. In other kinds of social insects, however, personalized relationships play little or no role. The sheer size of the colonies and the short life of the members make it inefficient, if not impossible, to establish individual bonds (Wilson, 1971).

As pointed out above (Section 1.26.2), the sheer unlimited capacity of honeybees to discriminate odors provides the potential for discrimination of a very large number of group constellations, even to the level of individual recognition. Only recently has it become possible to separately mark all individuals in a bee colony for automatic detection, and it will now be possible to track life history, behavior, and social contacts on an individual basis continuously over long periods of time.

Sociobiological arguments have been put forward to argue that due to haplodiploid reproduction in 
hymenopteran societies their members should be characterized by less individuality, more generelated group effects, and some form of individuality of the society (Queller and Strassmann, 2002). From a cognitive point of view, individuals are defined by the operations within their nervous systems, and their experience that this nervous system belongs to a particular body. As Churchland (2002, p. 310) points out "Body-state signals have to be integrated, options evaluated, and choices made, since the organism needs to act as a coherent whole, not as a group of independent systems with competing interests." Body-state signals are continuously integrated in members of an insect society, options are implicitly evaluated as indicated in the communicative processes, and the individual organism acts within the society. As in the case of implicit operations on working memories (representations), individual recognition within the society does not require the assumption of any form of explicit (personal) recognition of oneself and another member of the society. In this sense, one may use the modern techniques to search for discrimination on the individual level in communication within insect societies.

\subsubsection{Collective Cognition}

So far, we have concentrated on individual cognitive capabilities, because learning and memory are properties which depend on individual experience and which have to be studied, therefore, at the individual level. However, individuals of many species live in societies or form groups, and therefore face problems that require coordination, task sharing, and collective decision making. From this perspective, it is legitimate to ask whether collective behaviors reflect or even surpass individual plasticity, due, for instance, to the possible additive effect of individual cognitive capacities.

This question has been the subject of debate in social insects in which colonies were considered 'superorganisms' (Seeley, 1989; Southwick, 1983; Wilson and Sober, 1989). From this point of view, it has been argued that the 'superorganism' protects and constitutes itself thanks to colony recognition systems based on cuticular hydrocarbons which are transferred between individuals within the colony, thus obscuring, in theory, individual identity (Queller and Strassmann, 2002). The metaphor of the 'superorganism' may be in a sense misleading, because an individual, behaving organism is made from cells and structures tightly interconnected by complex neuronal, circulatory, and regulatory networks, and has a central brain that commands and produces behavior; the 'superorganism', on the other hand, is made up of individuals which may be interconnected by complex chemical interactions but which are rather autonomous and can be hardly compared to constituent cells. The essential difference, however, is that although an insect colony produces collective behavior, it does not have a central brain to command and control such behavior. On the contrary, studies on collective decision making in social insects show that collective behavioral patterns can arise without any central control. How, then, can these patterns of collective behavior emerge? This question has been intensively tackled by studies focusing on self-organization models of collective behavior (Camazine et al., 2003). Such studies deal with pattern formation processes in the physical and biological world, which determine the arising of global order and structure based on simple interactions between lower-level components, in this case, individuals (see above: decision making in a bee swarm).

Such studies have allowed researchers to understand that - despite their potential complexity many collective insect behavior patterns emerge from simple interactions between individuals, which seem to act on the basis of extremely simple behavioral rules. For instance, cockroaches and other insects seeking refuge exhibit complex aggregation phenomena and group distribution between available shelters. Instead of resulting from individual decision making and evaluation and comparison of each refuge's characteristics, collective aggregation results from individual probabilistic rules determining when to stop walking or when to resume. Factors like the presence of borders or of a co-specific may amplify these probabilities like a snowball (i.e., the larger the cluster, the higher the probability of attracting even more individuals; see Theraulaz et al., 2003) but the collective behavioral pattern emerges without central control or individual comparison strategies (Jeanson et al., 2003, 2005). Similarly, complex architectural structures characterizing ant or termite nests arise without central control, simply based on a restricted set of individual behaviors performed in a rather automatic way, without 'knowledge' of the behavioral patterns exhibited by other individuals (Buhl et al., 2004). Ants facing a diamond-shaped bridge with two branches choose randomly between branches if both are identical but collectively orient their choice and select one branch if it has a lateral wall along its edge. Pharaoh ants walking the wrong way along a trail are unable to reorient at a trail bifurcation if the angle is $120^{\circ}$, but can if the angle is smaller (Ratnieks, 2005). Such a collective systematic 
choice does not result from a sum of individual evaluations and decisions but from amplification processes based on physical heterogeneities and chemical communication (Dussoutour et al., 2005). Thus, a preference is set without a clear incidence of individual decision making and comparison. Differences in individual thresholds for reacting to environmental sensory stimuli seem to be a critical factor for the emergence of collective behaviors based on task partitioning. Not all individuals within a group will respond similarly to the same set of environmental stimuli such that differences in reaction thresholds may be the basis for behavioral specializations and thus for the emergence of sociality.

The conclusion emerging from these studies on insect collective behavior is that individuals, which may be viewed as extremely sophisticated at the cognitive level when performing some individual tasks, appear as automatons with limited cognitive capacities when performing collective tasks. This difference may seem puzzling, because it could be that cognitive richness is lost or at least temporally inhibited in a social context. What, for instance, drives a honeybee scout, which is able to learn space in the form of a cognitive map (Menzel et al., 2005) and learns the localization of a potential nest site and its physical characteristics (Seeley, 1982), to follow dances once, at random, in the hive, instead of crossing over and comparing dances for selected sites in the process of nest selection (Visscher and Camazine, 1999)? In fact, it can be argued that the question does not actually make sense from the point of view of the individual insect: in an individual and in a social context, the animal will adopt the behavioral strategies leading to adaptive solutions either boosting or sacrificing what researchers would view as cognitive sophistication. The critical question in this context is therefore what determines the adoption of one or the other level of cognitive complexity? Which factors are responsible for the fact that an ant or a bee that can learn and memorize several cues while foraging solve complex discriminations and generate novel behaviors leading to adaptive solutions, behave like an automaton following a reduced set of repetitive patterns and simple rules in a social context? Which physiological changes, if any, determine the passage from one state to the other? Do social regulation pheromones intervene in the expression or inhibition of behavioral autonomy in a social context by acting on neurotransmitter levels in the insect nervous system? So far, we have no answers to these questions, but they can be approached on an experimental level. Studying whether or not individual learning and memory are modified by exposure to social pheromones or by chemosensory cues within a group and whether or not biogenic amine and neurotransmitter levels are changed in the presence of a group of co-specifics are just some of the paths that can be followed to provide some answers to these questions.

\subsubsection{Conclusion}

The environment poses the same basic demands on animals with small and with large brains. How do mates find each other, how much effort, risk, energy, and time must be invested to find food, what is the best way for the animal to protect itself and avoid predators or hazardous conditions, and how does the animal find its way around are questions that have to be answered both by vertebrates and invertebrates in order to survive. It is usually concluded that invertebrates, with their smaller brains, apply local solutions to these problems, that is, solutions that are specific and isolated, local in a verbal, a mechanistic, and a behavioral sense. Verbally, a localized solution may mean that it may suit only a problem at a particular location in space and time. Mechanistically, local solutions may mean that only specific sensory-motor connections in the nervous system may exist with no crosstalk between them and no common level of memory storage. Behaviorally, local solutions refer to independent behavior routines that are applied without gaining from each other in different environmental conditions. In other words, the concept of information transfer between sensory-motor routines, translated in the rise of novel behaviors that allow responding to novel environmental demands, seems to be neglected or minimized in the case of invertebrates.

Our review provides multiple indications as evidence against such an understanding, which ignores the enormous richness of invertebrate behavior, its high flexibility, and the cross-talk between different behavioral routines. Rather, it is appropriate to conceptualize invertebrate behavior from a cognitive perspective, meaning that small nervous systems also interconnect the sensory and motor systems, and install memories not only into specific sensory-motor circuits but into a common reference system as well. As a consequence, many invertebrate species that were studied in this respect were found to extract rules from particular sequences of experience and transfer these rules to other sensory domains. Furthermore, the structure of the memory established in this way represents the multiple sensory inputs and related behaviors in an integrated 
way such that a representation of complex environmental conditions is formed. Such capacities may not be surprising when the underlying neural substrate subserving them is explored in detail. As in larger brains, two basic neural architectural principles of many invertebrate brains are: the existence of specialized neuropiles, which refer to specific sensory domains, and higher-order integration centers, in which information pertaining to these different domains converges and is integrated, thus allowing cross-talking and information transfer. In this sense, both modularity and central integration seem to be basic building principles adopted by different nervous systems to provide flexible solutions to a changing environment. Navigation and communication in social Hymenoptera are particularly telling examples in this respect, but it is fair to conclude that similar integrated forms of dealing with the environment will be found in other invertebrates when they are looked at more closely. In this sense, research addressing behavioral complexity and its underlying neural substrates is necessary to characterize the real potential of invertebrate learning and memory. Usually such an approach has been used to characterize behavioral simplicity rather than complexity. It therefore seems timely to focus on the latter by studying problem solving besides elemental forms of learning.

One of the major questions of behavioral biology in general is also unresolved for invertebrate behavior: the relationship between innate and acquired behavior. Innate behavior can often be considered highly integrated in the sense that rather complex motor performances are adequately expressed in particular stimulus combinations. The 'intelligence' of these integrated systems stems from the specific activation of such innate behavioral components in the animal's motivational conditions and the often less obvious experience-dependent adaptations. We have tried to capture these complex interactions between innate components, motivation, and acquired memory by coining the terms 'phylogenetic memory' and 'experience-dependent individual memory'. Indeed, both forms of stored information are based on the intimate connectivity of the nervous system, and from the point of view of how memory is retrieved it may not matter how the relevant memory has been stored. Rather, it seems crucial for the organization of memories and the expression of resulting behaviors how memory is acquired, that is, to which natural conditions do memories provide solutions. The intimacy between phylogenetic and experience-dependent memory is reflected in the fact that innate and acquired information can often not be separated in any given behavior. Although we have stressed the point that the richness and flexibility of acquiring information through experience is the key issue in a cognitive perspective of invertebrate behavior, it should not be overlooked that innate components cannot be considered less cognitive if they are closely connected with flexibility and adaptiveness. To which extent innate components constitute real limitations of invertebrate behavior must be analyzed in an ecological and evolutionary perspective which takes into account the evolutionary consequences of innate behaviors. Invertebrates provide us with an enormous range of solutions to these integrated forms of dealing with changing environmental conditions and the animal's needs. Ideally, more studies on invertebrate behavior will be inspired by this cognitive perspective.

\section{References}

Abrams, T. W. and Kandel, E. R. 1988. Is contiguity detection in classical conditioning a system or a cellular property? Learning in Aplysia suggests a possible molecular site. Trends Neurosci. 11, 128-135.

Adamo, S. A. and Hoy, R. R. 1995. Agonistic behavior in male and female field crickets, Gryllus bimaculatus, and how behavioural context influences its expression. Anim. Behav. 49, 1491-1501.

Alexander, R. D. 1961. Aggressiveness, territorality, and sexual behaviour in field crickets (Orthoptera: Gyllidae). Behaviour 17, 130-223.

Balleine, B. W. 2001. Incentive processes in instrumental conditioning. In: Handbook of Contemporary Learning Theories (ed. R. M. S. Klein), pp. 307-366. Hillsdale.

Barth, F. G. 2002. Spider senses - technical perfection and biology. Zoology 105, 271-285.

Benard, J. and Giurfa, M. 2004. A test of transitive inferences in free-flying honeybees: Unsuccessful performance due to memory constraints. Learn. Mem. 11, 328-336.

Bennett, A. T. D. 1996. Do animals have cognitive maps? J. Exp. Biol. 199, 219-224.

Ben Shahar, Y., Robichon, A., Sokolowski, M. B., and Robinson, G. E. 2002. Influence of gene action across different time scales on behavior. Science 296, 741-744.

Bermudez, J. L. 2003. Thinking without Words. Oxford University Press.

Bertolucci, F. 2003. Characterization of learning and memory in Drosophila S6Kii (ignorant) mutants in classical conditioning. In: Dipartimento di Biologia, p. 67. Universitá di Padova.

Botzer, D., Markovich, S., and Susswein, A. J. 1998. Multiple memory processes following training that a food is inedible in Aplysia. Learn. Mem. 5, 204-219.

Brembs, B. 2003a. Operant conditioning in invertebrates. Curr. Opin. Neurobiol. 13, 710-717.

Brembs, B. 2003b. Operant reward learning in Aplysia. Curr. Dir. Psychol. Sci. 12, 218-221.

Brembs, B. and Heisenberg, M. 2000. The operant and the classical in conditioned orientation in Drosophila melanogaster at the flight simulator. Learn. Mem. 7, 104-115.

Brembs, B. and Heisenberg, M. 2001. Conditioning with compound stimuli in Drosophila melanogaster in the flight simulator. J. Exp. Biol. 204, 2849-2859. 
Brembs, B., Lorenzetti, F. D., Reyes, F. D., Baxter, D. A., and Byrne, J. H. 2002. Operant reward learning in Aplysia: Neuronal correlates and mechanisms. Science 296, 1706-1709.

Brembs, B., Baxter, D. A., and Byrne, J. H. 2004. Extending in vitro conditioning in Aplysia to analyze operant and classical processes in the same preparation. Learn. Mem. 11, 412-420.

Brigui, N., Le Bourg, E., and Medioni, J. 1990. Conditioned suppression of the proboscis-extension response in young, middle-aged, and old Drosophila melanogaster flies: Acquisition and extinction. J. Comp. Psychol. 104, 289-296.

Brogden, J. W. 1939. Unconditional stimulus-substitution in the conditioning process. Am. J. Psychol. 52, 46-55.

Buck, J. and Case, J. 2002. Physiological links in firefly flash code evolution. J. Insect Behav. 15, 51-68.

Buhl, J., Gautrais, J., Deneubourg, J. L., and Theraulaz, G. 2004. Nest excavation in ants: Group size effects on the size and structure of tunnelling networks. Naturwissenschaften 92, 602-606.

Byrne, J. H. 2002. Invertebrate learning. In: Learning and Memory (ed. J. H. Byrne), pp. 273-291. MacMillan Reference Books.

Byrne, J. H., Baxter, D. A., Buonomano, D. V., and Raymond, J. L. 1990. Neuronal and network determinants of simple and higher-order features of associative learning: Experimental and modeling approaches. Cold Spring Harb. Symp. Quant. Biol. 55, 175-186.

Camazine, S., Deneubourg, J. L., Franks, N., Sneyd, J., Theraulaz, G., and Bonabeau, E. 2003. Self-Organization in Biological Systems. Princeton University Press.

Capaldi, E. A., Smith, A. D., Osborne, J. L., et al. 2000. Ontogeny of orientation flight in the honeybee revealed by harmonic radar. Nature 403, 537-540.

Carew, T. J. 2002. Aplysia: Development of processes underlying learning. In: Learning and Memory (ed. J. H. Byrne), pp. 37-41. MacMillan Reference Books.

Carew, T. J., Walters, E. T., and Kandel, E. R. 1981. Associative learning in Aplysia: Cellular correlates supporting a conditioned fear hypothesis. Science 211, 501-504.

Carew, T. J., Hawkins, R. D., and Kandel, E. R. 1983. Differential classical conditioning of a defensive withdrawal reflex in Aplysia californica. Science 219, 397-400.

Carew, T. J., Hawkins, R. D., Abrams, T. W., and Kandel, E. R. 1984. A test of Hebb's postulate at identified synapses which mediate classical conditioning in Aplysia. J. Neurosci. 4, 1217-1224.

Carlin, N. F. and Schwartz, P. H. 1989. Pre-imaginal experience and nestmate brood recognition in the carpenter ant, Camponotus floridanus. Anim. Behav. 38, 89-95.

Chandra, S. and Smith, B. H. 1998. An analysis of synthetic processing of odor mixtures in the honeybee. J. Exp. Biol. 201, 3113-3121.

Chiel, H. J. and Susswein, A. J. 1993. Learning that food is inedible in freely behaving Aplysia californica. Behav. Neurosci. 107, 327-338.

Chittka, L. and Geiger, K. 1995. Can honeybees count landmarks? Anim. Behav. 49, 159-164.

Chittka, L., Gumbert, A., and Kunze, J. 1997. Foraging dynamics of bumble bees: Correlates of movements within and between plant species. Behav. Ecol. 8, 239-249.

Churchland, P. S. 2002. Self-representation in nervous systems. Science 296, 308-310.

Clayton, N. S., Bussey, T. J., and Dickinson, A. 2003a. Can animals recall the past and plan for the future? Nat. Rev. Neurosci. 4, 685-691.
Clayton, N. S., Bussey, T. J., Emery, N. J., and Dickinson, A. 2003b. Prometheus to Proust: The case for behavioural criteria for 'mental time travel'. Trends Cogn. Sci. 7, 436-437.

Cocroft, R. B. 2003. The social environment of an aggregating, ant-attended treehopper. J. Insect Behav. 16, 79-95.

Cocroft, R. B. and Rodriguez, R. L. 2005. The behavioral ecology of insect vibrational communication. BioScience 55, 323-334.

Collett, T. S. 1996. Insect navigation en route to the goal: Multiple strategies for the use of landmarks. J. Exp. Biol. 199, 227-235.

Collett, T. S. 1998. Rapid navigational learning in insects with a short lifespan. Connect. Sci. 10, 255-270.

Collett, T. S. and Collett, M. 2000. Path integration in insects. Curr. Opin. Neurobiol. 10, 757-762.

Collett, T. S. and Collett, M. 2002. Memory use in insect visual navigation. Nat. Rev. Neurosci. 3, 542-552.

Collett, M., Harland, D., and Collett, T. S. 2002. The use of landmarks and panoramic context in the performance of local vectors by navigating honeybees. J. Exp. Biol. 205, 807-814.

Colwill, R. M., Absher, R. A., and Roberts, M. L. 1988. ContextUS learning in Aplysia californica. J. Neurosci. 8, 4434-4439.

Crow, T. 2004. Pavlovian conditioning of Hermissenda: Current cellular, molecular, and circuit perspectives. Learn. Mem. 11, 229-238.

Cunningham, J. P., Moore, C. J., Zalucki, M. P., and West, S. A. 2004. Learning, odour preference and flower foraging in moths. J. Exp. Biol. 207, 87-94.

Daly, K. C. and Smith, B. H. 2000. Associative olfactory learning in the moth Manduca sexta. J. Exp. Biol. 203, 2025-2038.

Darmaillacq, A. S., Chichery, R., Poirier, R., and Dickel, L. 2004a. Effect of early feeding experience on subsequent prey preference by cuttlefish Sepia officinalis. Dev. Psychobiol. 45, 239-244.

Darmaillacq, A. S., Dickel, L., Chichery, M.-P., Agin, V., and Chichery, R. 2004b. Rapid taste aversion learning in adult cuttlefish, Sepia officinalis. Anim. Behav. 68, 1291-1298.

Darwin, C. 1882. The formation of vegetable mould through the action of worms with observations of their habitats. Appleton 1969. Reprint. International Publication Service.

Deisig, N., Lachnit, H., Hellstern, F., and Giurfa, M. 2001. Configural olfactory learning in honeybees: Negative and positive patterning discrimination. Learn. Mem. 8, 70-78.

Deisig, N., Lachnit, H., and Giurfa, M. 2002. The effect of similarity between elemental stimuli and compounds in olfactory patterning discriminations. Learn. Mem. 9, 112-121.

Deisig, N., Lachnit, H., Sandoz, J. C., Lober, K., and Giurfa, M. 2003. A modified version of the unique cue theory accounts for olfactory compound processing in honeybees. Learn. Mem. 10, 199-208.

DeJianne, D., McGuire, T. R., and Pruzan-Hotchkiss, A. 1985. Conditioned suppression of proboscis extension in Drosophila melanogaster. J. Comp. Psychol. 99, 74-80.

De Marco, R. J. and Menzel, R. 2005. Encoding spatial information in the waggle dance. J. Exp. Biol. 208, 3885-3894.

D'Ettorre, P. and Heinze, J. 2001. Sociobiology of slave-making ants. Acta Ethol. 3, 67-82.

D'Ettorre, P., Mondy, N., Lenoir, A., and Errard, C. 2002. Blending in with the crowd: Social parasites integrate into their host colonies using a flexible chemical signature. Proc. Biol. Sci. 269, 1911-1918.

Devaud, J. M., Acebes, A., Ramaswami, M., and Ferrus, A. 2003. Structural and functional changes in the olfactory pathway of 
adult Drosophila take place at a critical age. J. Neurobiol. 56, 13-23.

Dickinson, A. and Balleine, B. W. 2002. The role of learning in the operation of motivational systems. In: Learning, Motivation \& Emotion, Volume 3 of Steven's Handbook of Experimental Psychology (ed. C. R. Gallistel), 3rd edn., pp. 497-533. Wiley.

Dobson, H. E. 1989. Possible roles of pollenkitt in flower selection by bees: An overview. In: Experimental Studies in Pollination and Pollinator Foraging Efficiency $(e d$. S. L. Buchmann), pp. 1-51. Berkeley.

Dubnau, J., Grady, L., Kitamoto, T., and Tully, T. 2001. Disruption of neurotransmission in Drosophila mushroom body blocks retrieval but not acquisition of memory. Nature 411, 476-480.

Dudai, Y. 2002. Invertebrate learning: Drosophila. In: Learning and Memory (ed. J. H. Byrne), pp. 292-296. MacMillan Reference Books.

Dudai, Y. 2004. The neurobiology of consolidations, or, how stable is the engram? Annu. Rev. Psychol. 55, 51-86.

Dudai, Y. and Eisenberg, M. 2004. Rites of passage of the engram: Reconsolidation and the lingering consolidation hypothesis. Neuron 44, 93-100.

Dussoutour, A., Deneubourg, J. L., and Fourcassie, V. 2005. Amplification of individual preferences in a social context: The case of wall-following ant. Proc. R. Soc. Lond. B 272, 705-714.

Dyer, F. C. 1991. Honey bees acquire route-based memories but not cognitive maps in a familiar landscape. Anim. Behav. 41, 239-246.

Dyer, F. C. 1998. Spatial cognition: Lessons from central-place foraging insects. In: Animal Cognition in Nature (eds. R. Balda, I. Pepperburg, and A. Kamil), pp. 119-154. Academic Press.

Dyer, F. C. 2002. The biology of the dance language. Annu. Rev. Entomol. 47, 917-949.

Dyer, A. G. and Chittka, L. 2004. Fine colour discrimination requires differential conditioning in bumblebees. Naturwissenschaften 91, 224-227.

Dyer, F. C. and Gould, J. L. 1981. Honey bee orientation: A backup system for cloudy days. Science 214, 1041-1042.

Dyer, F. C., Gill, M., and Sharbowski, J. 2002. Motivation and vector navigation in honey bees. Naturwissenschaften 89 , 262-264.

Ebbinghaus, H. 1964. Memory. A Contribution to Experimental Psychology. Dover (originally published in 1885).

Edwards, C. and Lofty, J. R. 1972. Biology of Earthworms. Chapman and Hall.

Egelhaaf, M. and Kern, R. 2002. Vision in flying insects. Curr. Opin. Neurobiol. 12, 699-706.

Eisner, T. and Aneshansley, D. 1973. Ultraviolet patterns on rear of flowers: Basis of disparity of buds and blossoms. Proc. Natl. Acad. Sci. USA 70, 1002-1004.

Eisner, T. and Meinwald, J. 1995. The chemisty of sexual selection. Proc. Natl. Acad. Sci. USA 92, 50-55.

Ellison, G. D. and Konorski, J. 1964. Separation of the salivary and motor responses in instrumental conditioning. Science 146, 1071-1072.

Engel, J. E., Xie, X.-J., Sokolowski, M. B., and Wu, C.-F. 2000. A cGMP-dependent protein kinase gene, foraging, modifies habituation-like response decrement of the giant fiber escape circuit in Drosophila. Learn. Mem. 7, 341-352.

Erber, J., Pribbenow, B., Kisch, J., and Faensen, D. 2000. Operant conditioning of antennal muscle activity in the honey bee (Apis mellifera L.). J. Comp. Physiol. A: Sens. Neural Behav. Physiol. 186, 557-565.
Esch, H. E. and Burns, J. E. 1995. Honeybees use optic flow to measure the distance of a food source. Die Naturwiss. 82, 38-40.

Esch, H. E., Zhang, S., Srinivasan, M. V., and Tautz, J. 2001. Honeybee dances communicate distances measured by optic flow. Nature 411, 581-583.

Etienne, A. S., Maurer, R., Boulens, V., Levy, A., and Rowe, T. 2004. Resetting the path integrator: A basic condition for route-based navigation. J. Exp. Biol. 207, 1491-1508.

Fan, R. J. and Hansson, B. S. 2001. Olfactory discrimination conditioning in the moth Spodoptera littoralis. Physiol. Behav. 72, 159-165.

Fan, R. J., Anderson, P., and Hansson, B. 1997. Behavioural analysis of olfactory conditioning in the moth Spodoptera littoralis (Boisd.) (Lepidoptera: Noctuidae). J. Exp. Biol. 200 (Part 23), 2969-2976.

Fauria, K., Colborn, M., and Collett, T. S. 2000. The binding of visual patterns in bumblebees. Curr. Biol. 10, 935-938.

Fauria, K., Dale, K., Colborn, M., and Collett, T. S. 2002. Learning speed and contextual isolation in bumblebees. J. Exp. Biol. 205, 1009-1018.

Feany, M. B. and Quinn, W. G. 1995. A neuropeptid gene defined by the Drosophila memory mutant amnesiac. Science 268 , 869-873.

Fersen, L.v., Wynne, C. D. L., and Delius, J. D. 1990. Deductive reasoning in pigeons. Die Naturwiss. 77, 548-549.

Fiorito, G. and Chichery, R. 1995. Lesions of the vertical lobe impair visual discrimination learning by observation in Octopus vulgaris. Neurosci. Lett. 192, 117-120.

Fiorito, G. and Scotto, P. 1992. Social learning in invertebrates. Comments on this paper and author's response. Science 256, 545-547.

Fiorito, G., Agnisola, C., d'Addio, M., Valanzano, A., and Calamandrei, G. 1998. Scopolamine impairs memory recall in Octopus vulgaris. Neurosci. Lett. 253, 87-90.

Fox, K., Bienenstock, E., Bonhoeffer, T., et al. 1998. To what extent are activity-dependent processes common to development and learning? In: Mechanistic Relationships between Development and Learning: Beyond Metaphor (eds. T. Carew, R. Menzel, and C. J. Shatz), pp. 163-188. Wiley.

Fresquet, N. 1999. Effects of aging on the acquisition and extinction of excitatory conditioning in Drosophila melanogaster. Physiol. Behav. 67, 205-211.

von Frisch, K. 1967. The Dance Language and Orientation of Bees. Harvard University Press.

von Frisch, K. 1968. The role of dances in recruiting bees to familiar sites. Anim. Behav. 16, 531-533.

Fulton, D., Kemenes, I., Andrew, R. J., and Benjamin, P. R. 2005. A single time-window for protein synthesis-dependent longterm memory formation after one-trial appetitive conditioning. Eur. J. Neurosci. 21, 1347-1358.

Gallistel, C. R. 1990. The Organization of Learning. MIT Press.

Gandolfi, M., Mattiacci, L., and Dorn, S. 2003. Preimaginal learning determines adult response to chemical stimuli in a parasitic wasp. Proc. Biol. Sci. 270, 2623-2629.

Geervliet, J. B. F., Vreugdenhil, A. I., Dicke, M., and Vet, L. E. M. 1998. Learning to discriminate between infochemicals from different plant-host complexes by the parasitoids Cotesia glomerata and C. rubecula (Hym: Braconidae). Entomol. Exp. Appl. 86, 241-252.

Gerber, B. and Menzel, R. 2000. Contextual modulation of memory consolidation. Learn. Mem. 7, 151-158.

Gerber, B. and Ullrich, J. 1999. No evidence for olfactory blocking in honeybee classical conditioning. J. Exp. Biol. 202, 1839-1854. 
Gerhardt, H. C. and Huber, F. 2002. Acoustic Communication in Insects and Anurans. The University of Chicago Press.

Gillner, S. and Mallot, H. A. 1998. Navigation and acquisition of spatial knowledge in a virtual maze. J. Cogn. Neurosci. 10, 445-463.

Giurfa, M. 2003. Cognitive neuroethology: Dissecting non-elemental learning in a honeybee brain. Curr. Opin. Neurobiol. 13, 726-735.

Giurfa, M. 2004. Conditioning procedure and color discrimination in the honeybee Apis mellifera. Naturwissenschaften 91, 228-231.

Giurfa, M. and Capaldi, E. A. 1999. Vectors, routes and maps: New discoveries about navigation in insects. Trends Neurosci. 22, 237-242.

Giurfa, M. and Malun, D. 2004. Associative mechanosensory conditioning of the proboscis extension reflex in honeybees. Learn. Mem. 11, 294-302.

Giurfa, M., Núñez, J. A., Chittka, L., and Menzel, R. 1995. Colour preferences of flower-naive honeybees. J. Comp. Physiol. (A) 177, 247-259.

Giurfa, M., Hammer, M., Stach, S., Stollhoff, N., MullerDeisig, N., and Mizyrycki, C. 1999. Pattern learning by honeybees: Conditioning procedure and recognition strategy. Anim. Behav. 57, 315-324.

Giurfa, M., Zhang, S., Jenett, A., Menzel, R., and Srinivasan, M. V. 2001. The concepts of 'sameness' and 'difference' in an insect. Nature 410, 930-933.

Giurfa, M., Schubert, M., Reisenman, C., Gerber, B., and Lachnit, H. 2003. The effect of cumulative experience on the use of elemental and configural visual discrimination strategies in honeybees. Behav. Brain Res. 145, 161-169.

Götz, K. G. 1975. The optomotor equilibrium of the Drosophila navigation system. J. Comp. Physiol. 99, 187-210.

Gould, J. L. and Gould, C. G. 1982. The Insect Mind: Physics or Metaphysics? In: Animal Mind-Human Mind (ed. D. R. Griffin), pp. 269-297. Springer.

Graham, P. and Collett, T. S. 2002. View-based navigation in insects: How wood ants (Formica rufa L.) look at and are guided by extended landmarks. J. Exp. Biol. 205, 2499-2509.

Gray, J. M., Hill, J. J., and Bargmann, C. I. 2005. Inaugural article: A circuit for navigation in Caenorhabditis elegans. Proc. Natl. Acad. Sci. USA 102, 3184-3191.

Greenspan, R. J. and van Swinderen, B. 2004. Cognitive consonance: Complex brain functions in the fruit fly and its relatives. Trends Neurosci. 27, 707-711.

Greggers, U. and Menzel, R. 1993. Memory dynamics and foraging strategies of honeybees. Behav. Ecol. Sociobiol. 32, 17-29.

Griffin, D. R. 1984. Animal Thinking. Harvard University Press.

Grünbaum, L. and Müller, U. 1998. Induction of a specific olfactory memory leads to a long-lasting activation of protein kinase $\mathrm{C}$ in the antennal lobe of the honeybee. J. Neurosci. 18, 4384-4392.

Gumbert, A. 2000. Color choices by bumble bees (Bombus terrestris): Innate preferences and generalization after learning. Behav. Ecol. Sociobiol. 48, 36-43.

Guo, J. and Guo, A. 2005. Crossmodal interactions between olfactory and visual learning in Drosophila. Science 309, 307-310.

Hammer, M. 1993. An identified neuron mediates the unconditioned stimulus in associative learning in honeybees. Nature 366, 59-63.

Hammer, M. 1997. The neural basis of associative reward learning in honeybees. Trends Neurosci. 20, 245-252.

Haney, J. and Lukowiak, K. 2001. Context learning and effect of context on memory retrieval in Lymnaea. Learn. Mem. 8, $35-43$.
Hartlieb, E., Anderson, P., and Hansson, B. S. 1999. Appetitive learning of odours with different behavioural meaning in moths. Physiol. Behav. 67, 671-677.

Hawkins, R. D., Abrams, T. W., Carew, T. J., and Kandel, E. R. 1983. A cellular mechanism of classical conditioning in Aplysia: Activity-dependent amplification of presynaptic facilitation. Science 219, 400-405.

Hawkins, R. D., Carew, T. J., and Kandel, E. R. 1986. Effects of interstimulus interval and contingency on classical conditioning of the Aplysia siphon withdrawal reflex. J. Neurosci. 6, 1695-1701.

Hawkins, R. D., Lalevic, N., Clark, G. A., and Kandel, E. R. 1989. Classical conditioning of the Aplysia siphon-withdrawal reflex exhibits response specificity. Proc. Natl. Acad. Sci. USA 86, 7620-7624.

Hawkins, R. D., Cohen, T. E., Greene, W., and Kandel, E. R. 1998. Relationships between dishabituation, sensitization, and inhibition of the gill- and siphon-withdrawal reflex in Aplysia californica: Effects of response measure, test time, and training stimulus. Behav. Neurosci. 112, 24-38.

Heisenberg, M. 2003. Mushroom body memoir: From maps to models (review). Nat. Rev. Neurosci. 4, 266-275.

Heisenberg, M., Wolf, R., and Brembs, B. 2001. Flexibility in a single behavioral variable of Drosophila. Learn. Mem. 8, $1-10$.

Hellstern, F., Wüstenberg, D., and Hammer, M. 1995. Contextual learning in honeybees under laboratory conditions. In: Learning and Memory (eds. N. Elsner and R. Menzel), Proceedings of the 23rd Göttingen Neurobiology Conference, p. 30. Geortg Thieme Verlag.

Hellstern, F., Malaka, R., and Hammer, M. 1998. Backward inhibitory learning in honeybees: A behavioral analysis of reinforcement processing. Learn. Mem. 4, 429-444.

Henry, C. S. 1994. Singing and cryptic speciation in insects. Trends Ecol. Evol. 9, 388-392.

Hermitte, G., Pedreira, M. E., Tomsic, D., and Maldonado, H. 1999. Context shifts and protein synthesis inhibition disrupt long-term habituation after spaced, but not massed, training in the crab Chasmagnathus. Learn. Mem. 71, 34-49.

Hölldobler, B. and Roces, F. 2000. The behavioral ecology of stridulatory communication in leafcutting ants. In: Model Systems in Behavioral Ecology: Integrating Empirical, Theoretical and Conceptual Approaches (ed. L. Dugatkin), pp. 92-109. Princeton University Press.

Hölldobler, B. and Wilson, E. O. 1990. The Ants. Springer.

Holliday, M. and Hirsch, J. 1986. Excitatory conditioning of individual Drosophila melanogaster. J. Exp. Psychol. Anim. Behav. Process. 12, 131-142.

Hornstein, E. P., O'Carroll, D. C., Anderson, J. C., and Laughlin, S. B. 2000. Sexual dimorphism matches photoreceptor performance to behavioral requirements. Proc. R. Soc. 267, 2111-2117.

Isabel, G., Pascual, A., and Preat, T. 2004. Exclusive consolidated memory phases in Drosophila. Science 304, 1024-1027.

Isingrini, M., Lenoir, A., and Jaisson, P. 1985. Pre-imaginal learning for colony brood recognition in the ant Cataglyphis cursor. Fonsc. Proc. Natl. Acad. Sci. USA 82, 8545-8547.

Jackson, R. R. and Li, D. 2004. One-encounter search-image formation by araneophagic spiders. Anim. Cogn. 7, 247-254.

Jaffe, K. and Blanco, M. E. 1994. Involvement of amino acids, opioids, nitric oxide, and NMDA receptors in learning and memory consolidation in crickets. Pharmacol. Biochem. Behav. 47, 493-496.

Jeanson, R., Blanco, S., Fournier, R., Deneubourg, J. L., Fourcassie, V., and Theraulaz, G. 2003. A model of animal movements in a bounded space. J. Theor. Biol. 225, 443-451. 
Jeanson, R., Rivault, C., Deneubourg, J. L., et al. 2005. Selforganized aggregation in cockroaches. Anim. Behav. 69, 169-180.

Jones, N. G., Kemenes, I., Kemenes, G., and Benjamin, P. R. 2003. A persistent cellular change in a single modulatory neuron contributes to associative long-term memory. Curr. Biol. 13, 1064-1069.

Kamin, L. J. 1968. Attention-like processes in classical conditioning. In: Miami Symposion on Predictability, Behavior and Aversive Stimulation (ed. M. R. Jones), pp. 9-32. Miami University Press.

Kandel, E. R. 2001. The molecular biology of memory storage: A dialogue between genes and synapses. Science 294, 1030-1038.

Kandel, E. R. and Schwartz, J. H. 1982. Molecular biology of learning: Modulation of transmitter release. Science 218, 433-443.

Kandel, E. R. and Squire, L. R. 1992. Cognitive neuroscience. Curr. Opin. Neurobiol. 2(2), 143-145.

Kandel, E. R., Krasne, F. B., Strumwasser, F., and Truman, J. W. 1979. Cellular mechanisms in the selection and modulation of behavior. Neurosci. Res. Program Bull. 17, 521-710.

Kandel, E. R., Abrams, T., Bernier, L., Carew, T. J., Hawkins, R. D., and Schwartz, J. H. 1983. Classical conditioning and sensitization share aspects of the same molecular cascade in Aplysia. Cold Spring Harb. Symp. Quant. Biol. 48(Part 2), 821-830.

Kartsev, V. M. 1996. Local orientation: Learning in insects. In: Russian Contributions to Invertebrate Behavior (eds. C. I. Abramson, Z. P. Shuranova, and Y. M. Burmistrov), pp. 177-212. Praeger.

Katzoff, A., Ben-Gedalya, T., and Susswein, A. J. 2002. Nitric oxide is necessary for multiple memory processes after learning that a food is inedible in Aplysia. J. Neurosci. 22, 9581-9594.

Kemenes, I., Kemenes, G., Andrew, R. J., Benjamin, P. R., and O'Shea, M. 2002. Critical time-window for NO-cGMPdependent long-term memory formation after one-trial appetitive conditioning. J. Neurosci. 22, 1414-1425.

Kimmel, H. D. 1977. Notes from 'Pavlov's Wednesdays': Sensory preconditioning. Am. J. Psychol. 90, 319-321.

Kisch, J. and Erber, J. 1999. Operant conditioning of antennal movements in the honey bee. Behav. Brain Res. 99, 93-102.

Klatzky, R. L. 1998. Allocentric and egocentric spatial representations: Definitions, distinctions and interconnections. In: Spatial Cognition: An Interdisciplinary Approach to Representing and Processing Spatial Knowledge (eds. C. Freksa, C. Habel, and K. F. Wender), pp. 1-17. Springer.

Kohler, M. and Wehner, R. 2005. Idiosyncratic route-based memories in desert ants, Melophorus bagoti: How do they interact with path-integration vectors? Neurobiol. Learn. Mem. 83, 1-12.

Komischke, B., Sandoz, J. C., Lachnit, H., and Giurfa, M. 2003. Non-elemental processing in olfactory discrimination tasks needs bilateral input in honeybees. Behav. Brain Res. 145, 135-143.

Komischke, B., Sandoz, J.-C., Malun, D., and Giurfa, M. 2005. Partial unilateral lesions of the mushroom bodies affect olfactory learning in honeybees Apis mellifera. L. Eur. J. Neurosci. 21, 477-485.

Korneev, S. A., Straub, V., Kemenes, I., et al. 2005. Timed and targeted differential regulation of nitric oxide synthase (NOS) and anti-NOS genes by reward conditioning leading to longterm memory formation. J. Neurosci. 25, 1188-1192.

Kupfermann, I. 1974. Feeding behavior in Aplysia: A simple system for the study of motivation. Behav. Biol. 10, 1-26.
Kwon, H. W., Lent, D. D., and Strausfeld, N. J. 2004. Spatial learning in the restrained American cockroach Periplaneta americana. J. Exp. Biol. 207, 377-383.

Lachnit, H., Giurfa, M., and Menzel, R. 2004. Odor processing in honeybees: Is the whole equal to, more than, or different from the sum of its parts? In: Advances in the Study of Behavior (eds. P. J. G. Slater, et al.), vol. 34, pp. 241-264. Elsevier.

Lall, A. B. 1993. Nightly increase in visual sensitivity correlated with bioluminescent flashing activity in the firefly Photuris versicolor (Coleoptera: Lampyridae). J. Exp. Zool. 265, 609-612.

Law, E., Nuttley, W. M., and van der Kooy, D. 2004. Contextual taste cues modulate olfactory learning in C. elegans by an occasion setting mechanism. Curr. Biol. 14, 1303-1308.

Lechner, H. A., Baxter, D. A., and Byrne, J. H. 2000a. Classical conditioning of feeding in Aplysia. II: Neurophysiological correlates. J. Neurosci. 20, 3377-3386.

Lechner, H. A., Baxter, D. A., and Byrne, J. H. 2000b. Classical conditioning of feeding in Aplysia. I: Behavioral analysis. J. Neurosci. 20, 3369-3376.

Lenoir, A., D’Ettorre, P., Errard, C., and Hefetz, A. 2001. Chemical ecology and social parasitism in ants. Annu. Rev. Entomol. 46, 573-599.

Lent, D. D. and Kwon, H. W. 2004. Antennal movements reveal associative learning in the American cockroach Periplaneta americana. J. Exp. Biol. 207, 369-375.

Lindauer, M. 1955. Schwarmbienen auf Wohnungssuche. Zeitschrift fuer vergleichende Physiologie 37, 263-324.

Linster, C. and Smith, B. H. 1997. A computational model of the response of honey bee antennal circuitry to odor mixtures: Overshadowing, blocking and unblocking can arise from lateral inhibition. Behav. Brain Res. 87, 1-14.

Liu, L., Wolf, R., Ernst, R., and Heisenberg, M. 1999. Context generalization in Drosophila visual learning requires the mushroom bodies. Nature 400, 753-756.

Livermore, A., Hutson, M., Ngo, V., Hadjisimos, R., and Derby, C. D. 1997. Elemental and configural learning and the perception of odorant mixtures by the spiny lobster Panulirus argus. Physiol. Behav. 62, 169-174.

Lukowiak, K. and Syed, N. 1999. Learning, memory and a respiratory central pattern generator. Comp. Biochem. Physiol. A Mol. Integr. Physiol. 124, 265-274.

Lukowiak, K., Ringseis, E., Spencer, G., Wildering, W., and Syed, N. 1996. Operant conditioning of aerial respiratory behaviour in Lymnaea stagnalis. J. Exp. Biol. 199, 683-691.

Lukowiak, K., Cotter, R., Westly, J., Ringseis, E., and Spencer, G. 1998. Long-term memory of an operantly conditioned respiratory behaviour pattern in Lymnaea stagnalis. J. Exp. Biol. 201, 877-882.

Lukowiak, K., Adatia, N., Krygier, D., and Syed, N. 2000. Operant conditioning in Lymnaea: Evidence for intermediateand long-term memory. Learn. Mem. 7, 140-150.

Lukowiak, K., Sangha, S., McComb, C., et al. 2003. Associative learning and memory in Lymnaea stagnalis: How well do they remember? J. Exp. Biol. 206, 2097-2103.

Mackintosh, N. J. 1975. A theory of attention: Variations in the associability of stimuli with reinforcement. Psychol. Rev. 82, 276-298.

Malun, D. 1998. Early development of mushroom bodies in the brain of the honeybee Apis mellifera as revealed by BrdU incorporation and ablation experiments. Learn. Mem. 5, 90-101.

Matsumoto, Y. and Mizunami, M. 2002. Temporal determinants of long-term retention of olfactory memory in the cricket Gryllus bimaculatus. J. Exp. Biol. 205, 1429-1437. 
Matsumoto, Y. and Mizunami, M. 2004. Context-dependent olfactory learning in an insect. Learn. Mem. 11, 288-293.

Matsumoto, Y., Noji, S., and Mizunami, M. 2003. Time course of protein synthesis-dependent phase of olfactory memory in the cricket Gryllus bimaculatus. Zool. Sci. 20, 409-416.

Mazokhin-Porschnyakov, G. A. and Kartsev, V. M. 1994. Learning in bees and wasps in complicated experimental tasks. In: Prerational Intelligence: Adaptive Behavior and Intelligent Systems without Symbols and Logic (eds. H. Ritter, H. Cruse, and J. Dean), vol. 2, pp. 449-467. Kluwer.

McCall, P. J. and Eaton, G. 2001. Olfactory memory in the mosquito Culex quinquefasciatus. Med. Vet. Entomol. 15, 197-203.

McComb, C., Sangha, S., Qadry, S., Yue, J., Scheibenstock, A., and Lukowiak, K. 2002. Context extinction and associative learning in Lymnaea. Neurobiol. Learn. Mem. 78, 23-34.

McComb, C., Meems, R., Syed, N., and Lukowiak, K. 2003. Electrophysiological differences in the neuronal circuit controlling aerial respiratory behaviour between juvenile and adult Lymnaea. J. Neurophysiol. 90, 983-992.

Medioni, J. and Vaysse, G. 1975. Conditional suppression of a reflex in Drosophila melanogaster: Acquisition and extinction. C. R. Seances Soc. Biol. Fil. 169, 1386-1391.

Menzel, R. 1967. Untersuchungen zum Erlernen von Spektralfarben durch die Honigbiene (Apis mellifica). Zeitschrift fuer vergleichende Physiologie 56, 22-62.

Menzel, R. 1985. Learning in honey bees in an ecological and behavioral context. In: Experimental Behavioral Ecology and Sociobiology (eds. B. Hölldobler and M. Lindauer), pp. 55-74. Gustav Fischer Verlag.

Menzel, R. 1990. Learning and cognition in honey bees. In: Neurobiology of Comparative Cognition (eds. R. P. Kesner and D. S. Olton), pp. 237-292. Erlbaum.

Menzel, R. 1999. Memory dynamics in the honeybee. J. Comp. Physiol. (A) 185, 323-340.

Menzel, R. 2001. Behavioral and neural mechanisms of learning and memory as determinants of flower constancy. In: Cognitive Ecology of Pollination. Animal Behavior and Floral Evolution (eds. L. Chittka and J. D. Thomson), pp. 21-40. Cambridge University Press.

Menzel, R. and Giurfa, M. 2001. Cognitive architecture of a mini-brain: The honeybee. Trends Cogn. Sci. 5, 62-71.

Menzel, R. and Müller, U. 1996. Learning and memory in honeybees: From behavior to neural substrates. Annu. Rev. Neurosci. 19, 379-404.

Menzel, R., Geiger, K., Müller, U., Joerges, J., and Chittka, L. 1998. Bees travel novel homeward routes by integrating separately acquired vector memories. Anim. Behav. 55, 139-152.

Menzel, R., Brandt, R., Gumbert, A., Komischke, B., and Kunze, J. 2000. Two spatial memories for honeybee navigation. Proc. R. Soc. Lond. B 267, 961-968.

Menzel, R., Manz, G., Menzel, R. M., and Greggers, U. 2001. Massed and spaced learning in honeybees: The role of CS, US, the inter-trial interval and the test interval. Learn. Mem. 8, 198-208.

Menzel, R., Greggers, U., Smith, A., et al. 2005. Honeybees navigate according to a map-like spatial memory. Proc. Natl. Acad. Sci. USA 102, 3040-3045.

Milner, B., Squire, L. R., and Kandel, E. R. 1998. Cognitive neuroscience and the study of memory. Neuron 20, 445-468.

Mizunami, M., Weibrecht, J. M., and Strausfeld, N. J. 1998. Mushroom bodies of the cockroach: Their participation in place memory. J. Comp. Neurol. 402, 520-537.

Morris, R. G. M. 1982. New approaches to learning and memory. Trends Neurosci. 8, 3-4.
Mozzachiodi, R., Lechner, H., Baxter, D., and Byrne, J. 2003. An in vitro analogue of classical conditioning of feeding in Aplysia. Learn. Mem. 10, 478-494.

Müller, D., Gerber, B., Hellstern, F., Hammer, M., and Menzel, R. 2000. Sensory preconditioning in honeybees. J. Exp. Biol. 203, 1351-1364.

Müller, G. E. and Pilzecker, A. 1900. Experimentelle Beiträge zur Lehre vom Gedächtnis. Z. Psychol. 1, 1-288.

Müller, U. 1996. Inhibition of nitric oxide synthase impairs a distinct form of long-term memory in the honeybee, Apis mellifera. Neuron 16, 541-549.

Müller, U. 2000. Prolonged activation of cAMP-dependent protein kinase during conditioning induces long-term memory in honeybees. Neuron 27, 159-168.

Nader, K. 2003. Memory traces unbound. Trends Neurosci. 26, 65-72.

Nargeot, R., Baxter, D. A., and Byrne, J. H. 1997. Contingentdependent enhancement of rhythmic motor patterns: An in vitro analog of operant conditioning. J. Neurosci. 17, 8093-8105.

Nargeot, R., Baxter, D. A., and Byrne, J. H. 1999a. In vitro analog of operant conditioning in Aplysia. I: Contingent reinforcement modifies the functional dynamics of an identified neuron. J. Neurosci. 19, 2247-2260.

Nargeot, R., Baxter, D. A., and Byrne, J. H. 1999b. In vitro analog of operant conditioning in Aplysia. II: Modifications of the functional dynamics of an identified neuron contribute to motor pattern selection. J. Neurosci. 19, 2261-2272.

Nargeot, R., Baxter, D. A., Patterson, G. W., and Byrne, J. H. 1999c. Dopaminergic synapses mediate neuronal changes in an analogue of operant conditioning. J. Neurophysiol. 81, 1983-1987.

Nolen, T. G. and Carew, T. J. 1988. The cellular analog of sensitization in Aplysia emerges at the same time in development as behavioral sensitization. J. Neurosci. 8(1), 212-222.

Nunez, J., Almeida, L., Balderrama, N., and Giurfa, M. 1997. Alarm pheromone induces stress analgesia via an opioid system in the honeybee. Physiol. Behav. 63, 75-80.

O'Keefe, J. and Nadel, J. 1978. The Hippocampus as a Cognitive Map. Oxford University Press.

Otto, F. 1959. Die Bedeutung des Rückfluges für die Richtungsund Entfernungsangabe der Bienen. Zeitschrift fuer vergleichende Physiologie 42, 303-333.

Pascual, A. and Preat, T. 2001. Localization of long-term memory within the Drosophila mushroom body. Science 294, 1115-1117.

Pastergue-Ruiz, I. R., Beugnon, G., and Lachaud, J. P. 1995. Can the ant Cataglyphis cursor (Hymenoptera: Formicidae) encode global landmark-landmark relationships in addition to isolated landmark-goal relationships? J. Insect Behav. 8, 115-132.

Pavlov, I. P. 1927. Conditioned Reflexes. Oxford University Press.

Pearce, J. M. 1994. Similarity and discrimination: A selective review and a connectionist model. Psychol. Rev. 101, 587-607.

Pedreira, M. E. and Maldonado, H. 2003. Protein synthesis subserves reconsolidation or extinction depending on reminder duration. Neuron 38, 863-869.

Pinter, M., Lent, D. D., and Strausfeld, N. J. 2005. Memory consolidation and gene expression in Periplaneta americana. Learn. Mem. 12, 30-38.

Potting, R. P. J., Otten, H., and Vet, L. E. M. 1997. Absence of odour learning in the stemborer parasitoid Cotesia flavipes. Anim. Behav. 53, 1211-1223.

Premack, D. and Premack, A. J. 1983. The Mind of the Ape. Norton.

Putz, G. 2003. Characterization of memories and ignorant (S6KII) mutants in operant conditioning in the heat-box. 
In: Department of Genetics and Neurobiology, p. 115. JuliusMaximilians-Universität Würzburg.

Putz, G. and Heisenberg, M. 2002. Memories in Drosophila heatbox learning. Learn. Mem. 9, 349-359.

Putz, G., Bertolucci, F., Raabe, T., Zars, T., and Heisenberg, M. 2004. The S6KII (rsk) gene of Drosophila melanogaster differentially affects an operant and a classical learning task. J. Neurosci. 24, 9745-9751.

Queller, D. C. and Strassmann, J. E. 2002. The many selves of social insects. Science 296, 311-313.

Rankin, C. H. 2000. Context conditioning in habituation in the nematode Caenorhabditis elegans. Behav. Neurosci. 114, 496-505.

Rankin, C. H. 2004. Invertebrate learning: What can't a worm learn? Curr. Biol. 14, R617-R618.

Ratnieks, F. 2005. Outsmarted by ants. Nature 436, 465.

Redhead, E. S. and Pearce, J. M. 1995. Stimulus salience and negative patterning. Q. J. Exp. Psychol. B 48, 67-83.

Reif, M. 1998. The evolution of learning - a study in Drosophila melanogaster. In: Department of Genetics, p. 131. JuliusMaximilians Universität Würzburg.

Rescorla, R. A. 1968. Probability of shock in the presence and absence of CS in fear conditioning. J. Comp. Physiol. Psychol. 66, 1-5.

Rescorla, R. A. and Wagner, A. R. 1972. A theory of classical conditioning: Variations in the effectiveness of reinforcement and non-reinforcement. In: Classical Conditioning. II: Current Research and Theory (eds. A. H. Black and W. F. Prokasy), pp. 64-99. Appleton Century Crofts.

Robertson, I. 2001. Problem Solving. Psychology Press.

Rodger, S., Griffiths, B. S., McNicol, J. W., Wheatley, R. W., and Young, I. M. 2004. The impact of bacterial diet on the migration and navigation of Caenorhabditis elegans. Microb. Ecol. 48, 358-365.

Rodriguez, I., Gumbert, A., Hempel de Ibarra, N., Kunze, J., and Giurfa, M. 2004. Symmetry is in the eye of the 'beeholder': Innate preference for bilateral symmetry in flower-naive bumblebees. Naturwissenschaften 91, 374-377.

Ronacher, B., Gallizzi, K., Wohlgemuth, S., and Wehner, R. 2000. Lateral optic flow does not influence distance estimation in the desert ant Cataglyphis fortis. J. Exp. Biol. 203, 1113-1121.

Rudy, J. W. and Sutherland, R. J. 1992. Configural and elemental associations and the memory coherence problem. J. Cogn. Neurosci. 4(3), 208-216.

Rudy, J. W. and Sutherland, R. J. 1995. Configural association theory and the hippocampal formation: An appraisal and reconfiguration. Hippocampus 5, 375-389.

Sandoz, J.-C. and Menzel, R. 2001. Side-specificity of olfactory learning in the honeybee: Generalization between odors and sides. Learn. Mem. 8, 286-294.

Sangha, S., McComb, C., Scheibenstock, A., Johannes, C., and Lukowiak, K. 2002. The effects of continuous versus partial reinforcement schedules on associative learning, memory and extinction in Lymnaea stagnalis. J. Exp. Biol. 205, 1171-1178.

Sangha, S., McComb, C., and Lukowiak, K. 2003. Forgetting and the extension of memory in Lymnaea. J. Exp. Biol. 206, $71-77$.

Scheibenstock, A., Krygier, D., Haque, Z., Syed, N., and Lukowiak, K. 2002. The Soma of RPeD1 must be present for long-term memory formation of associative learning in Lymnaea. J. Neurophysiol. 88, 1584-1591.

Schmajuk, N. A. and Holland, P. 1998. Occasion Setting: Associative Learning and Cognition in Animals, p. 440. American Psychological Association.
Schubert, M., Francucci, S., Lachnit, H., and Giurfa, M. 2005. Nonelemental visual learning in honeybees. Anim. Behav. 64, 175-184.

Schwaerzel, M., Monastirioti, M., Scholz, H., Friggi-Grelin, F., Birman, S., and Heisenberg, M. 2003. Dopamine and octopamine differentiate between aversive and appetitive olfactory memories in Drosophila. J. Neurosci. 23, 10495-10502.

Schwarz, M. and Susswein, A. J. 1984. A neural pathway for learning that food is inedible in Aplysia. Brain Res. 294, 363-366.

Schwarz, M. and Susswein, A. J. 1986. Identification of the neural pathway for reinforcement of feeding when Aplysia learn that food is inedible. J. Neurosci. 6, 1528-1536.

Schwarz, M. and Susswein, A. J. 1992. Presence of conspecifics facilitates learning that food is inedible in Aplysia fasciata. Behav. Neurosci. 106, 250-261.

Schwarz, M., Feldman, E., and Susswein, A. J. 1991. Variables affecting long-term memory of learning that a food is inedible in Aplysia. Behav. Neurosci. 105, 193-201.

Scotto-Lomassese, S., Strambi, C., Strambi, A., et al. 2003. Suppression of adult neurogenesis impairs olfactory learning and memory in an adult insect. J. Neurosci. 23, 9289-9296.

Seeley, T. D. 1977. Measurement of nest cavity volume by the honey bee (Apis mellifera). Behav. Ecol. Sociobiol. 2, 201-227.

Seeley, T. D. 1982. How honeybees find a home. Sci. Am. 247, $158-168$.

Seeley, T. D. 1989. The honey bee colony as a superorganism. Am. Scient. 77, 546-553.

Seeley, T. D. 1995. The Wisdom of the Hive - The Social Physiology of Honey Bee Colonies. Harvard University Press.

Seeley, T. D. and Visscher, P. K. 2004. Quorum sensing during nest-site selection by honeybee swarms. Behav. Ecol. Sociobiol. 56, 594-601.

Shelton, A. L. and McNamara, T. P. 1997. Multiple views of spatial memory. Psychon. Bull. Rev. 4, 102-106.

Skiri, H. T., Stranden, M., Sandoz, J. C., Menzel, R., and Mustaparta, H. 2005. Associative learning of plant odorants activating the same or different receptor neurones in the moth Heliothis virescens. J. Exp. Biol. 208, 787-796.

Smith, B. H. and Cobey, S. 1994. The olfactory memory of the honey bee, Apis mellifera. II: Blocking between odorants in binary mixtures. J. Exp. Biol. 195, 91-108.

Southwick, E. E. 1983. The honey bee cluster as a homeothermic superorganism. Comp. Biochem. Physiol. 75A, 641-645.

Spencer, G. E., Syed, N. I., and Lukowiak, K. 1999. Neural changes after operant conditioning of the aerial respiratory behavior in Lymnaea stagnalis. J. Neurosci. 19, 1836-1843.

Spencer, G. E., Kazmi, M. H., Syed, N. I., and Lukowiak, K. 2002. Changes in the activity of a CpG neuron after the reinforcement of an operantly conditioned behavior in Lymnaea. J. Neurophysiol. 88, 1915-1923.

Srinivasan, M. V. and Zhang, S. 2004. Visual motor computations in insects. Annu. Rev. Neurosci. 27, 679-696.

Srinivasan, M. V., Zhang, S., Altwein, M., and Tautz, J. 2000a. Honeybee navigation: Nature and calibration of the 'odometer'. Science 287, 851-853.

Srinivasan, M. V., Zhang, S., and Bidwell, N. 2000b. Visually mediated odometry in honeybees. J. Exp. Biol. 200, 2513-2522.

Staras, K., Kemenes, I., Benjamin, P. R., and Kemenes, G. 2003. Loss of self-inhibition is a cellular mechanism for episodic rhythmic behavior. Curr. Biol. 13, 116-124.

Steidl, S. and Rankin, C. H. 2002. Invertebrate learning: C. elegans. In: Learning and Memory (ed. J. H. Byrne), pp. 287-291. MacMillan Reference Books. 
Stollhoff, N., Menzel, R., and Eisenhardt, D. 2005. Spontaneous recovery from extinction depends on the reconsolidation of the acquisition memory in an appetitive learning paradigm in the honeybee (Apis mellifera). J. Neurosci. 25, 4485-4492.

Straub, V. A., Styles, B. J., Ireland, J. S., O'Shea, M., and Benjamin, P. R. 2004. Central localization of plasticity involved in appetitive conditioning in Lymnaea. Learn. Mem. 11, 787-793.

Suddendorf, T. and Busby, J. 2003. Mental time travel in animals? Trends Cogn. Sci. 7, 391-396.

Susswein, A. J. and Schwarz, M. 1983. A learned change of response to inedible food in Aplysia. Behav. Neural Biol. 39, 1-6.

Susswein, A. J., Schwarz, M., and Feldman, E. 1986. Learned changes of feeding behavior in Aplysia in response to edible and inedible foods. J. Neurosci. 6, 1513-1527.

Sutherland, R. J. and Rudy, J. W. 1989. Configural association theory: The role of the hippocampal formation in learning, memory, and amnesia. Psychobiology 17(2), 129-144.

Sutton, R. S. and Barto, A. G. 1998. Reinforcement Learning. MIT Press.

Tarsitano, M. S. and Jackson, R. R. 1997. Araneophagic jumping spiders discriminate between detour routes that do and do not lead to prey. Anim. Behav. 53, 257-266.

Tautz, J., Rohrseitz, K., and Sandeman, D. C. 1996. One-strided waggle dance in bees. Nature 382, 32.

Tautz, J., Zhang, S., Spaethe, J., Brockmann, A., Si, A., and Srinivasan, M. 2004. Honeybee odometry: Performance in varying natural terrain. PLoS. Biol. 2, E211.

Terrace, H. S. and McGonigle, B. 1994. Memory and representation of serial order by children, monkeys and pigeons. Curr. Dir. Psychol. Sci. 3, 180-185.

Theraulaz, G., Gautrais, J., Camazine, S., and Deneubourg, J. L. 2003. The formation of spatial patterns in social insects: From simple behaviours to complex structures. Philos. Trans. R. Soc. Lond. A 361, 1263-1282.

Thielin-Bescond, M. and Beugnon, G. 2005. Vision-independent odometry in the ant Cataglyphis cursor. Naturwissenschaften 92, 193-197.

Thinus-Blanc, C. 1987. The cognitive map concept and its consequences. In: Cognitive Processes and Spatial Orientation in Animal and Man (eds. P. Ellen and C. Thinus-Blanc), pp. 1-18. Martinus Nijhoff Publ.

Tibbetts, E. A. 2002. Visual signals of individual identity in the wasp Polistes fuscatus. Proc. Biol. Sci. 269, 1423-1428.

Tibbetts, E. A. and Dale, J. 2004. A socially enforced signal of quality in a paper wasp. Nature 432, 218-222.

Tinbergen, N. 1960. The natural control of insects in pine woods. Vol. I: Factors influencing the intensity of predation by songbirds. Arch. Neerland. Zool. 13, 265-343.

Tolman, E. C. 1948. Cognitive maps in rats and men. Psychol. Rev. 55, 189-208.

Tully, T. 1991. Of mutations affecting learning and memory in Drosophila - the missing link between gene product and behavior. Trends Neurosci. 14, 163-164.

Tully, T. and Quinn, W. G. 1985. Classical conditioning and retention in normal and mutant Drosophila melanogaster. J. Comp. Physiol. (A) 157, 263-277.

Tully, T., Preat, T., Boynton, S. C., and Del Vecchio, M. 1994. Genetic dissection of consolidated memory in Drosophila. Cell 79, 35-47.

van Swinderen, B. and Greenspan, R. J. 2003. Salience modulates $20-30 \mathrm{~Hz}$ brain activity in Drosophila. Nat. Neurosci. 6, 579-586.

Verschure, P. F., Voegtlin, T., and Douglas, R. J. 2003. Environmentally mediated synergy between perception and behaviour in mobile robots. Nature 425, 620-624.
Vet, L. E. M. 1996. Parasitoid foraging: The importance of variation in individual behaviour for population dynamics. In: Frontiers of Population Ecology (eds. R. B. Floyd, A. W. Sheppard, and P. J. De Barro). CSIRO Publishing.

Vet, L. E. M., Lewis, W. J., and Cardé, R. T. 1995. Parasitoid foraging and learning. In: Chemical Ecology of Insects (eds. W. Bell and R. T. Cardé), pp. 65-101. Chapman and Hall.

Visscher, P. K. and Camazine, S. 1999. Collective decisions and cognition in bees. Nature 397, 400.

Walters, E. T. and Byrne, J. H. 1983a. Slow depolarization produced by associative conditioning of Aplysia sensory neurons may enhance $\mathrm{Ca}^{2+}$ entry. Brain Res. 280, 165-168.

Walters, E. T. and Byrne, J. H. 1983b. Associative conditioning of single sensory neurons suggests a cellular mechanism for learning. Science 219, 405-408.

Walters, E. T., Carew, T. J., and Kandel, E. R. 1979. Classical conditioning in Aplysia californica. Proc. Natl. Acad. Sci. USA 76, 6675-6679.

Walters, E.T, Carew, T. J., and Kandel, E. R. 1981. Associative learning in Aplysia: Evidence for conditioned fear in an invertebrate. Science 211, 504-506.

Watanabe, H., Kobayashi, Y., Sakura, M., Matsumoto, Y., and Mizunami, M. 2003. Classical olfactory conditioning in the cockroach Periplaneta americana. Zoolog. Sci. 20, 1447-1454.

Watanabe, H., Takaya, T., Shimoi, T., Ogawa, H., Kitamura, Y., and Oka, K. 2005. Influence of mRNA and protein synthesis inhibitors on the long-term memory acquisition of classically conditioned earthworms. Neurobiol. Learn. Mem. 83, 151-157.

Webb, B. 2004. Neural mechanisms for prediction: Do insects have forward models? Trends Neurosci. 27, 278-282.

Wehner, R. 1992. Arthropods. In: Animal Homing (ed. F. Papi), pp. 45-144. Chapman and Hall.

Wehner, R. 2003. Desert ant navigation: How miniature brains solve complex tasks. J. Comp. Physiol. A Neuroethol. Sens. Neural Behav. Physiol. 189, 579-588.

Wehner, R. and Menzel, R. 1990. Do insects have cognitive maps? Annu. Rev. Neurosci. 13, 403-414.

Wehner, R., Michel, B., and Antonsen, P. 1996. Visual navigation in insects: Coupling of egocentric and geocentric information. J. Exp. Biol. 199, 129-140.

Whitlow, J. W. and Wagner, A. R. 1972. Negative patterning in classical conditioning: Summation of response tendencies to isolable and configural components. Psychon. Sci. 27, 299-301.

Wilson, D. S. and Sober, E. 1989. Reviving the superorganism. J. Theor. Biol. 136, 337-356.

Wilson, E. O. 1971. The Insect Societies. Harvard University Press.

Wright, W. G., McCance, E. F., and Carew, T. J. 1996. Developmental emergence of long-term memory for sensitization in Aplysia. Neurobiol. Learn. Mem. 65, 261-268.

Wustmann, G. and Heisenberg, M. 1997. Behavioral manipulation of retrieval in a spatial memory task for Drosophila melanogaster. Learn. Mem. 4, 328-336.

Wustmann, G., Rein, K., Wolf, R., and Heisenberg, M. 1996. A new paradigm for operant conditioning of Drosophila melanogaster. J. Comp. Physiol. (A) 179, 429-436.

Zabala, N. A., Miralto, A., Maldonado, H., Núñez, J. A., Jaffe, K., and Calderon, L. d. C 1984. Opiate receptor in praying mantis: Effect of morphine and naloxone. Pharmacol. Biochem. Behav. 20, 683-687.

Zars, T., Wolf, R., Davis, R., and Heisenberg, M. 2000. Tissuespecific expression of a type I adenylyl cyclase rescues the 
rutabaga mutant memory defect: In search of the engram. Learn. Mem. 7, 18-31.

Zentall, T. R. 2005. Selective and divided attention in animals. Behav. Process. 69, 1-15.

Zentall, T. R. and Riley, D. A. 2000. Selective attention in animal discrimination learning. J. Gen. Psychol. 127, 45-66.

Zhang, S., Mizutani, A., and Srinivasan, M. V. 2000. Maze navigation by honeybees: Learning path regularity. Learn. Mem. 7, 363-374.

Zhang, S., Bock, F., Si, A., Tautz, J., and Srinivasan, M. V. 2005. Visual working memory in decision making by honey bees. Proc. Natl. Acad. Sci. USA 102, 5250-5255.

Zhang, S. W., Lehrer, M., and Srinivasan, M. V. 1999. Honeybee memory: Navigation by associative grouping and recall of visual stimuli. Neurobiol. Learn. Mem. 72, 180-201.
Zhang, S. W., Srinivasan, M. V., Zhu, H., and Wong, J. 2004. Grouping of visual objects by honeybees. J. Exp. Biol. 207, 3289-3298.

\section{Further Reading}

Byrne, J. H. (ed.) 2003. Learning and Memory. Macmillan Psychology Reference Series.

Carew, T. J. 2000. Behavioral Neurobiology. Sinauer Associates.

Gazzaniga, M. S. (ed.) 2004. The Congnitive Neurosciences (newest edition), Bradford Books. MIT Press.

Squire, L. R. (ed.) 1992. Encyclopedia of Learning and Memory. Macmillan.

Shettleworth, S. J. 2001. Animal cognition and animal behaviour. Anim. Behav. 61, 277-286. 